\title{
Hydrogen Sulfide Attenuates Calcification of Vascular Smooth Muscle Cells via KEAP1/NRF2/NQO1 Activation
}

Parisa Aghagolzadeh ${ }^{1,6}$, Ramin Radpour ${ }^{1}$, Matthias Bachtler ${ }^{1,6}$, Harry van Goor ${ }^{2}$, Edward R. Smith ${ }^{3}$, Adam Lister ${ }^{4,6}$, Alex Odermatt ${ }^{4,6}$, Martin Feelisch ${ }^{5}$, Andreas Pasch $^{1,6}$

${ }^{1}$ Department of Clinical Research, University of Bern, Switzerland

${ }^{2}$ Pathology and Medical Biology, University Medical Center Groningen and University of Groningen, the Netherlands

${ }^{3}$ Department of Nephrology, The Royal Melbourne Hospital, Melbourne, Victoria, Australia

${ }^{4}$ Division of Molecular \& Systems Toxicology, Department of Pharmaceutical Sciences, University of Basel, Basel, Switzerland

${ }^{5}$ Clinical and Experimental Sciences, Faculty of Medicine, Southampton General Hospital and Institute for Life Sciences, University of Southampton, Southampton, UK

${ }^{6}$ The National Centre of Competence in Research (NCCR) "Kidney.CH - Kidney Control of Homeostasis", Switzerland

Running title: Sulfide attenuates vascular calcification

Number of figures: 5

${ }^{*}$ Address for correspondence:

Dr. Andreas Pasch, MD

Department of Clinical Research

University of Bern

3010 Bern, Switzerland

Phone: +4131632 3037

E-mail: andreas.pasch@dkf.unibe.ch 


\begin{abstract}
Background and aims: Vascular calcification is a common health problem related to oxidative stress, inflammation, and circulating calciprotein particles (CPP). Hydrogen sulfide is an endogenous signaling molecule with antioxidant properties and potential for drug development targeting redox signaling. Yet, its molecular mechanisms of action in vascular smooth muscle cell (VSMC) calcification have not been delineated. We therefore sought to identify key pathways involved in the calcification-inhibitory properties of sulfide employing our recently developed CPP-induced VSMC calcification model.
\end{abstract}

Methods: Using next-generation sequencing, we investigated the transcriptomic changes of sodium hydrosulfide-treated versus non-treated calcifying VSMCs. The potential role of candidate genes and/or regulatory pathways in prevention of calcification was investigated by small interfering RNA (siRNA).

Results: CPP led to a pronounced accumulation of cell-associated calcium, which was decreased by sulfide in a concentration-dependent manner. Both, CPP-induced hydrogen peroxide production and enhanced pro-inflammatory/oxidative stress-related gene expression signatures were attenuated by sulfide-treatment. Gene ontology enrichment and in silico pathway analysis of our transcriptome data suggested $\mathrm{NAD}(\mathrm{P}) \mathrm{H}$ dehydrogenase [quinone] 1 (NQO1) as potential mediator. Corroborating these findings, silencing of Kelchlike ECH-associated protein 1 (KEAP1), an inhibitor of Nuclear factor (erythroid-derived 2)like 2 (NRF2) nuclear activity, enhanced NQO1 expression, whereas NRF2 silencing reduced the expression of NQO1 and abrogated the calcification-suppressing activity of sulfide. Moreover, immunofluorescence microscopy confirmed nuclear translocation of NRF2 by sulfide in VSMC.

Conclusions: Sulfide attenuates CPP-induced VSMC calcification in vitro via the KEAP1NRF2 redox sensing/stress response system by enhancing NQO1 expression.

Keywords: Vascular Smooth Muscle Cells, Calciprotein Particles, sulfide, $\mathrm{H}_{2} \mathrm{~S} / \mathrm{HS}^{-}, \mathrm{NQO} 1$ 


\begin{tabular}{ll}
\hline \multicolumn{2}{l}{ Nonstandard Abbreviations and Acronyms } \\
\hline VSMC & Vascular Smooth Muscle Cells \\
CKD & Chronic Kidney Disease \\
CPP & Calciprotein Particles \\
$\mathrm{H}_{2} \mathrm{~S}$ & Hydrogen sulfide \\
$\mathrm{NaHS}$ & Sodium hydrosulfide \\
$\mathrm{NGS}$ & Next Generation Sequencing \\
NQO1 & NAD(P)H dehydrogenase [quinone] 1 \\
NRF2 & Nuclear factor (erythroid-derived 2)-like 2 \\
KEAP1 & Kelch-like ECH-associated protein 1 \\
\hline
\end{tabular}




\section{Introduction}

Arterial medial calcification is the pathological deposition of calcium phosphate in the elastic layer of the blood vessel wall, leading to vascular stiffening and reduced vascular compliance with ageing. An increased propensity for soft tissue calcification is particularly prevalent in chronic kidney disease (CKD) patients, contributing to their markedly higher cardiovascular disease mortality compared to the general population [7, 15]. Accumulating evidence suggests that active cell-mediated processes contribute to the calcification process and that vascular smooth muscle cells (VSMC) are the main cell type affected [14]. Circulating complexes of calcium phosphate and plasma proteins called 'calciprotein particles' (CPP) have been found in the blood of CKD patients [17, 35], in the dialysate from patients receiving peritoneal dialysis [8], and in blood of patients with normal renal function suffering from rheumatoid arthritis [35]. CPP exist in the form of primary CPP, which are spherical nano-aggregates containing amorphous calcium phosphate, and secondary CPP, which are spindle-shaped and contain crystalline calcium phosphate. We have previously demonstrated that secondary CPP induce VSMC calcification in vitro and trigger the generation of reactive oxygen species (ROS), a process that is further enhanced by endogenous tumor necrosis factor- $\alpha$ [2].

Hydrogen sulfide $\left(\mathrm{H}_{2} \mathrm{~S}\right)$ has recently been identified as a gaseous signaling molecule with a wide range of physiological and pathological functions [39]. It is unclear whether dissolved $\mathrm{H}_{2} \mathrm{~S}$, its conjugate hydrosulfide anion (HS-) or secondary reaction products account for the biological effects observed. Nevertheless, $\mathrm{H}_{2} \mathrm{~S} / \mathrm{HS}^{-}$has been shown to reduce the production and/or attenuate the deleterious effects of pro-inflammatory cytokines, chemokines and ROS [6]. Physiologically, $\mathrm{H}_{2} \mathrm{~S} / \mathrm{HS}^{-}$is synthesized by the action of three enzymes of the trans-sulfuration pathway: cystathionine gamma-lyase (CSE), cystathionine beta-synthase (CBS) and 3-mercaptopyruvate sulfurtransferase (3-MST). Besides these enzymatic pathways, $\mathrm{H}_{2} \mathrm{~S} / \mathrm{HS}^{-}$can also be generated through non-enzymatic processes including the processing of inorganic and organic persulfides and polysulfides as well as elemental sulfur [25]. In fact, reactive sulfur species such as cysteine and protein hydropersulfides themselves may play an important role in redox biology [27]. $\mathrm{H}_{2} \mathrm{~S} / \mathrm{HS}^{-}$ appears to play important functions in the central nervous and cardiovascular system, and in the gastrointestinal and respiratory tract [38]. Specifically, aberrant endogenous $\mathrm{H}_{2} \mathrm{~S} / \mathrm{HS}^{-}$ metabolism, with likely consequences for systemic redox status, has been associated with hypertension, atherosclerosis, diabetes and Alzheimer's disease [38].

Both, endogenous $\mathrm{H}_{2} \mathrm{~S}$ synthesis and plasma concentrations of sulfide metabolites are reduced in CKD [5, 32]. Of note, pharmacological administration of $\mathrm{H}_{2} \mathrm{~S} / \mathrm{HS}^{-}$was shown to ameliorate vascular calcification load induced by vitamin D3 and nicotine feeding in rats 
[40], and also prevents calcification of VSMC in vitro [43]. Moreover, the endogenous $\mathrm{H}_{2} \mathrm{~S} / \mathrm{HS}^{-}$-precursor sodium thiosulfate (STS, $\mathrm{Na}_{2} \mathrm{~S}_{2} \mathrm{O}_{3}$ ), which is also available as a drug [28], attenuates the progression of vascular calcifications in CKD, both in animals and humans [1, 31].

To date, the molecular mechanisms underlying the protective effects of sulfide in VSMC calcification have not been delineated. We therefore sought to shed light on the mechanism(s) of $\mathrm{H}_{2} \mathrm{~S} / \mathrm{HS}^{-}$-mediated inhibition of CPP-induced calcification in cultured VSMC using a combination of high-throughput whole transcriptome analysis and RNA silencing. Here, we find that the sulfide donor NaHS ameliorates calcification in this system and that these beneficial effects are mediated by activation of the KEAP1/NRF2/NQO1 pathway. 


\section{Methods}

Primary Human Aortic Vascular Smooth Muscle Cells (VSMC) were exposed to control growth medium without CPP, growth medium supplemented with secondary CPP (final concentration equivalent to $50 \mu \mathrm{g} / \mathrm{mL}$ calcium) or growth medium supplemented concurrently with secondary CPP and sodium hydrosulfide for 24 hours. Mineralization was assessed qualitatively by staining with Alizarin Red $S$, and quantitatively by measurement of cellassociated calcium using the QuantiChrome calcium assay kit (Socochim) and normalized to cellular protein content. Cell viability was determined using MTT [3-(4,5-dime-thylthiazolyl-2)2,5-diphenyltetrazolium bromide] assay kit (BioVision).

Total RNA was extracted from VSMC lysates using the RNeasy Micro Kit (QIAGEN AG). For performing high-throughput transcriptome analysis using next generation sequencing (NGS), the library preparation was performed with 650ng of total RNA using the TruSeq Stranded mRNA Library Prep Kit (Illumina). The enriched RNA-seq libraries were sequenced using the NextSeq 500 High Output Kit 75-cycles (Illumina). The RNA-seq data was analyzed using the ArrayStar software v.12.2 (DNASTAR). Gene networks and canonical pathways representing differentially expressed genes were identified using the Ariadne Genomics Pathway Studio $®$ software (Elsevier). The potential role of candidate genes and/or regulatory pathways in prevention of calcification was investigated by quantitative real-time PCR, western blot, small interfering RNA (siRNA), nuclear and cytoplasmic extraction and Immunofluorescence microscopy. The complete details of methods are available in Supplementary data. 


\section{Results}

\section{Sulfide inhibits the calcification of VSMC}

To investigate the effects of sulfide on calcification, VSMC were exposed to secondary CPP (50 $\mathrm{\mu g} / \mathrm{mL}$ calcium), in the absence and presence of increasing NaHS concentrations. Calcium deposits at baseline were low in the absence of secondary CPP, but following incubation with secondary CPP, Alizarin staining was vastly increased, demonstrating enhanced mineralization of VSMC (Fig. 1A). This increase in calcification was significantly ameliorated by concomitant exposure of VSMC to NaHS, starting at a concentration of 100 $\mu \mathrm{mol} / \mathrm{L}$. CPP and NaHS, alone or in combination, did not impair cell viability up to a concentration of $300 \mu \mathrm{mol} / \mathrm{L}$ (Fig. 1C). The effective NaHS concentration for the ensuing experiments was selected as the one with maximum calcification prevention potency and concurrent minimum cytotoxicity ( $300 \mu \mathrm{mol} / \mathrm{L}$, Fig. 1B and 1C). Concentrations between 300 $\mu \mathrm{mol} / \mathrm{L}$ and $1000 \mu \mathrm{mol} / \mathrm{L}$ will exhibit increasing cell toxicity while further reducing calcification.

In summary, secondary CPP induced a pronounced accumulation of VSMCassociated calcium, whereas sulfide reduced this accrual in a concentration dependent manner.

\section{Sulfide ameliorates oxidative stress and cytokine expression in VSMC}

Using next-generation sequencing, we investigated the whole-transcriptome changes in NaHS-treated versus non-treated calcifying VSMC. The associated volcano plot illustrates the differential expression of more than 8000 genes (Fig. 2A). Further data analysis using a threshold fold change of 1.5 revealed that only 33 transcripts were significantly differentially up- or down-regulated between both groups (Fig. 2B and Suppl. Table 2). Gene Ontology enriched those genes into processes such as e.g. regulation of reactive oxygen species, response to hydrogen peroxide and inflammatory responses (Fig. 2C). Next, we used gene network analysis to explore the possible interactions among the 33 differentially expressed genes and selected cellular processes. This analysis revealed that 19 out of 33 genes are directly or indirectly involved in cellular responses to oxidative stress or inflammation (Fig. 2D). The expression of CCL2 and CXCL2 as representative inflammatory response genes; and $D K K 1$ and $R C A N 1$ genes as representative regulators for oxidative stress, were chosen for the validation of the NGS data using qRT-PCR (Fig. 2E). In order to validate the antioxidant effect of $\mathrm{NaHS}$, the levels of $\mathrm{H}_{2} \mathrm{O}_{2}$ in the supernatant were measured and revealed a significant reduction of peroxide accumulation upon sulfide treatment (Fig. 2F). Furthermore, exposure of VSMC to secondary CPP in the presence of NaHS led to a significant decrease of TNF- $\alpha$ mRNA. This is consistent with our previous work [2] and the anti-inflammatory activity of NaHS (Suppl. Fig.1). 
Among the differentially expressed genes, NQO1 is a well-characterised anti-oxidant protein, which was significantly upregulated upon NaHS treatment. Induction of NQO1 expression was confirmed by mRNA and protein analysis (Fig. 3A).

These results suggested that $\mathrm{H}_{2} \mathrm{~S} / \mathrm{HS}^{-}$may inhibit calcification via the anti-oxidative NQO1 pathway. Further analysis of the RNA-seq data revealed that NQO1 was upregulated in VSMC by sulfide irrespective of the presence of secondary CPP. Corroborating this effect of sulfide on NQO1 expression, we analyzed its concentration-response relationship in the absence of CPP and found that sulfide concentration-dependently induced the expression of NQO1 in VSMC at both mRNA and protein level (Fig. 3B).

In summary, $\mathrm{H}_{2} \mathrm{~S}$-induced upregulation of $\mathrm{NQO} 1$ was observed both in the presence and absence of CPP.

\section{Sulfide ameliorates VSMC calcification via increased expression of NQO1}

To investigate whether NaHS inhibits VSMC calcification via up-regulation of NQO1, siRNAmediated gene silencing experiments were performed. Transfection of VSMC with siNQO1 led to a significant reduction of NQO1 mRNA and protein (Fig. 3C), while a scrambled nucleotide sequence control siRNA, failed to reduce NQO1 (Fig. 3C). Importantly, when NQO1 was silenced, NaHS lost its protective effect on VSMC calcification, whereas treatment with scrambled siRNA did not abrogate the calcification inhibitory effects of $\mathrm{H}_{2} \mathrm{~S} / \mathrm{HS}^{-}$(Fig. 3D and 3E). Cell viability was not affected by siRNA-mediated gene silencing (Suppl. Fig.2). These results demonstrate that the anti-calcification properties of $\mathrm{H}_{2} \mathrm{~S}$ are mediated by the up-regulation of NQO1.

\section{NQO1 expression is regulated via KEAP1-NRF2 signaling}

In situations of oxidative stress the NQO1 gene is activated by the transcription factor NRF2 (nuclear factor, erythroid 2 like 2) [23]. Under normal conditions NRF2 is targeted by KEAP1 for ubiquitination and rapid proteasomal degradation [23]. We therefore analyzed the expression of NRF2 and KEAP1 in VSMC. Both genes were found to be constitutively highly expressed in VSMC at baseline. Upon treatment with secondary CPP or secondary CPP + NaHS, no significant changes in expression levels were observed (Fig. 4A).

To further elucidate the roles of NRF2 and KEAP1 proteins in the regulation of NQO1 by sulfide, we silenced each of these genes using specific siRNA. As shown in Figure 4B, siNRF2 significantly decreased the expression of both the NRF2 and NQO1 gene after 24 hours, without affecting KEAP1. By comparison, silencing of KEAP1 led to a significantly increased expression of NQO1 (Fig. 4B). Scrambled siRNA had no effect on NRF2, KEAP1 and NQO1 gene expression. Interestingly, KEAP1 siRNA also increased NQO1 at the protein level while NRF2 siRNA reduced it, consistent with their known molecular interactions (Fig. 
4C \& Suppl. Fig. 3). We also investigated the localization of NRF2 upon silencing of KEAP1. Immunofluorescence microscopy demonstrated an increased nuclear accumulation of NRF2 upon silencing of KEAP1 (Suppl. Fig. 4).

In aggregate, these data suggest that down-regulation of either NRF2 or KEAP1 significantly modulates sulfide-mediated NQO1 activity in VSMC.

\section{The role of KEAP1/NRF2/NQO1 in VSMC calcification}

To confirm the role of KEAP1 and NRF2 in mediating sulfide-induced inhibition of cellular calcification, we performed siRNA-mediated gene silencing of KEAP1 and NRF2 in VSMC. As shown in Figure 4D, sulfide ameliorated calcification when the KEAP1 gene was silenced whereas in contrast its calcification inhibiting effect was lost when NRF2 was silenced.

Taken together, these results are consistent with the hypothesis that sulfide attenuates VSMC calcification by NQO1 via activation of NRF2.

\section{Nuclear translocation of NRF2 upon $\mathrm{H}_{2} \mathrm{~S}$ treatment in VSMC}

Previous studies have identified NRF2 as a critical transcription factor that responds to oxidative stress [19, 24]. Signals from ROS inactivate KEAP1 and newly synthesized NRF2 bypasses KEAP1 and translocates into the nucleus where it activates its target genes [23]. Consistent with this notion, immunofluorescence microscopy and Western blot analysis demonstrated an increased nuclear accumulation of NRF2 in cells exposed to NaHS (Fig. 5A and $5 \mathrm{~B})$.

\section{Discussion}

Vascular calcification is a highly prevalent clinical problem in various disease settings including CKD, and VSMC are the main cell type affected by this process. Using an in vitro 
model of CPP-induced VSMC calcification in the present study we demonstrate that sulfide effectively prevents the mineralization process via an antioxidant-like effect. High-throughput transcriptomic profiling suggested a potential role of NQO1 in mediating the calcification inhibitory properties of sulfide. Besides confirming the protective effect of NQO1 induction using gene silencing, here we also demonstrate that $N Q O 1$ is under transcriptional control of the KEAP1/NRF2 pathway. NaHS treatment leads to NRF2 translocation into the nucleus and subsequent induction of NQO1. Collectively, our results suggest that VSMC calcification is an oxidant-driven process that is affected by changes in cellular redox status and can be modulated by administration of sulfide (Fig. 5C).

Previous studies have shown that elevated calcium and phosphate levels can promote VSMC calcification [33, 34, 47]. More specifically, we recently demonstrated that treatment of VSMC with secondary CPP leads to pronounced and concentration-dependent calcification [2]. Consistent with this finding, calcification has been linked to oxidative stress [3] as well as elevation of some inflammatory cytokines and C-reactive protein in CKD patients [22, 36]. An independent body of research has revealed that sulfide is involved in numerous physiological functions [39]. In the cardiovascular system, sulfide is predominantly produced by CSE in both, the endothelium and myocytes and involved in the regulation of myocardial contractility [13] as well as vascular tone [46]. A recent study in VSMC demonstrated that CSE is localized in the cytosol, but translocates to the mitochondria triggered by transient increases in cytoplasmic calcium. This leads to an increased intra-mitochondrial sulfide production, associated with an increase in ATP production [10]. There is currently no general consensus about the physiological concentrations of endogenous $\mathrm{H}_{2} \mathrm{~S}$ in the circulation [38], and elucidating optimal physiologic or therapeutic $\mathrm{H}_{2} \mathrm{~S}$-concentrations in more slowly calcifying in vivo models awaits clarification in future studies.

Interestingly, sulfide producing enzymes are downregulated in CKD patients [5, 32]. Consistent with this finding, plasma $\mathrm{H}_{2} \mathrm{~S}_{\text {HS }}^{-}$metabolite levels were also decreased in these patients [5, 32, 43]. A limitation of most of these studies is the use of a rather simple spectrophotometric method (the methylene blue assay) instead of a more specific analytical technique to measure circulating sulfide concentrations, raising a concern about what exactly was quantified there; [29] almost certainly, it was neither $\mathrm{H}_{2} \mathrm{~S}$ nor $\mathrm{HS}^{-}$as those concentrations are known to be extremely low (well below $1 \mu \mathrm{mol} / \mathrm{L}$ ). Of note, sodium thiosulfate, a precursor of sulfide and also a sulfane sulfur donor, prevented vascular calcification in uremic rats [31] and NaHS-treatment decreased it in vitamin D3 plus nicotinetreated rats [40]. Based on these observations, we investigated the role of sulfide in the prevention of VSMC calcification in our CPP-induced calcification system and observed that 
sulfide indeed vastly ameliorated calcification in this system. In our comparative wholetranscriptome analysis between secondary CPP and secondary CPP + NaHS group we found indications that sulfide inhibits calcification, at least in part, via its antioxidant properties. This result is consistent with in vivo data showing that sulfide protects myocytes from oxidative stress [13] and that it protects vascular endothelial function under oxidative stress conditions [4]. These results are in line with a previous observation showing that activation of Nrf2 by Resveratrol-ameliorated oxidative stress and vascular calcification [45].

The mechanisms responsible for the quenching of oxidative stress by sulfide deserve further consideration. One possible mechanism to reduce oxidative stress is via direct scavenging of ROS [4, 13]; while such possibility cannot be excluded with certainty, this mechanism is unlikely since sulfide is not a very strong reductant (its 1- and 2-electron redox potentials are not much different from those of other low-molecular weight thiols, yet its concentration in biological media is much lower). A second mechanism might be due to the upregulation of endogenous antioxidant defense systems [9, 21]. Regarding the first mechanism, it should be noted that the plasma sulfide concentration is in the submicromolar range [30] and basal free sulfide levels in mouse brain and liver homogenates were estimated to be approximately $5 \mathrm{nM}$ [11]. Such low concentrations cannot explain the potent antioxidant properties of sulfide. Furthermore, the antioxidant effect of sulfide in MC3T3-E1 osteoblastic cells was reported to last for at least 18 hours [41], incompatible with the high volatility of $\mathrm{H}_{2} \mathrm{~S}$. The major finding of our current study supports the hypothesis that sulfide acts as a trigger to up-regulate endogenous signaling mechanisms, which then reduce oxidative stress (Fig. 2). Using transcriptome analysis, we identified NQO1, a well-known antioxidant modulator, to account for the regulation of oxidative stress by $\mathrm{H}_{2} \mathrm{~S} / \mathrm{HS}^{-}$.

A common DNA regulatory cis-acting element, named anti-oxidant response element ARE, is present in the promoter region of the NQO1 gene and is targeted by the NRF2 protein $[20,37]$. Furthermore, inhibition of the redox sensor KEAP1 leads to NRF2 activation [23]. To analyze the underlying mechanisms of the upregulation of NQO1 by sulfide in VSMC, we investigated the expression of NRF2 and KEAP1 genes upon concomitant CPP + NaHS treatment. In our study, sulfide did not directly affect KEAP1 and NRF2 mRNA or protein expression. In contrast, we observed that NaHS treatment leads to overexpression of NQO1 and NRF2 translocation into the nucleus. These results are in line with a previous observation showing that $\mathrm{H}_{2} \mathrm{~S} / \mathrm{HS}^{-}$protects against cellular aging via KEAP1/NRF2 signaling despite the absence of an effect on the expression of these proteins [42]. However, an upregulation of NRF2 upon sulfide treatment was reported in other studies [12, 16].

A possible explanation for the absence of changes in NRF2 and KEAP1 protein expression despite their control over NQO1 is, that sulfide stimulates NRF2 nuclear translocation via the induction of post-translational modifications and/or conformational 
changes in KEAP1 [42]. KEAP1 contains three domains (BTB, IVR, Kelch) [42], 25 cysteine residues that are highly conserved among species [44] and at least two distinct cysteine motifs [42]. One of these motifs is located in the IVR domain and another one in the BTB domain $[18,44]$. The interaction of sulfide with the KEAP1 protein through a cysteine in the BTB domain has been shown to lead to S-sulfhydration of (i.e. formation of a persulfide on) KEAP1, triggering NRF2 dissociation from KEAP1 with consequently enhanced nuclear translocation of NRF2 [21, 42]. NRF2 translocation then further stimulates mRNA expression of NRF2 downstream targets, such as the NQO1 gene. Corroborating the importance of the KEAP1/NRF2/NQO1 system, further experiments in the present study revealed that silencing of NRF2 or KEAP1 genes using specific siRNA significantly affected the expression of NQO1 in VSMC and that impaired NRF2 activity aggravated the extent of calcification. Furthermore, the calcification inhibitory effect of sulfide was lost when NQO1 or the upstream transcription factor (NRF2) were silenced. In contrast, silencing of KEAP1 alone did not exhibit a strong influence on calcification although silencing of KEAP1 led to a small upregulation of NQO1. This suggests a ceiling effect at the NQO1 expression level.

Furthermore, as Matrix Gla Protein (MGP), a known strong mineralization inhibitor [26], was downregulated in our model upon NaHS treatment, this indicates that the calcificationsuppressing properties of NaHS are not mediated via MGP in our model (Suppl. Figure 5).

In conclusion, our data provide evidence that secondary CPP induce genes related to oxidative stress and inflammation, an effect ameliorated by the anti-oxidant activity of $\mathrm{H}_{2} \mathrm{~S} / \mathrm{HS}^{-}$. The latter is mediated by NQO1 and under regulatory control of the KEAP1/NRF2 pathway. These results may open potential novel strategies to prevent vascular calcification.

\section{Conflict of interest}

The authors declared that they do not have anything to disclose regarding conflict of interest with respect to this manuscript.

\section{Author contributions}

P.A. designed and performed experiments, analyzed and interpreted data and wrote the manuscript. R.R. and M.B. performed experiments and analyzed data. H. V. G, A.O., E.R.S. and A.L. designed experiments and interpreted data. M.F. designed experiments, interpreted data and wrote the manuscript. A.P. designed experiments, interpreted data, wrote the manuscript and supervised and organized the study. All authors revised the manuscript and approved its final version

\section{Acknowledgements}


We thank Willi Jahnen-Dechent, RWTH Aachen, Germany for critical reading and discussing the manuscript. AP and AO were supported by the National Center of Competence in Research, NCCR Kidney.ch (No. 403-11-21). 


\section{REFERENCES}

1. Adirekkiat S, Sumethkul V, Ingsathit A, Domrongkitchaiporn S, Phakdeekitcharoen B, Kantachuvesiri S, Kitiyakara C, Klyprayong P, Disthabanchong S (2010) Sodium thiosulfate delays the progression of coronary artery calcification in haemodialysis patients. Nephrology, dialysis, transplantation : official publication of the European Dialysis and Transplant Association - European Renal Association 25:1923-1929 doi:10.1093/ndt/gfp755

2. Aghagolzadeh $P$, Bachtler M, Bijarnia R, Jackson C, Smith ER, Odermatt A, Radpour R, Pasch A (2016) Calcification of vascular smooth muscle cells is induced by secondary calciprotein particles and enhanced by tumor necrosis factor-alpha. Atherosclerosis 251:404-414 doi:10.1016/j.atherosclerosis.2016.05.044

3. Agharazii M, St-Louis R, Gautier-Bastien A, Ung RV, Mokas S, Lariviere R, Richard DE (2014) Inflammatory Cytokines and Reactive Oxygen Species as Mediators of Chronic Kidney Disease-Related Vascular Calcification. Am J Hypertens. 28:746-755 doi:10.1093/ajh/hpu225

4. Al-Magableh MR, Kemp-Harper BK, Ng HH, Miller AA, Hart JL (2014) Hydrogen sulfide protects endothelial nitric oxide function under conditions of acute oxidative stress in vitro. Naunyn Schmiedebergs Arch Pharmacol 387:67-74 doi:10.1007/s00210-0130920-x

5. Aminzadeh MA, Vaziri ND (2012) Downregulation of the renal and hepatic hydrogen sulfide (H2S)-producing enzymes and capacity in chronic kidney disease. Nephrol Dial Transplant 27:498-504 doi:10.1093/ndt/gfr560

6. Bhatia M (2012) Role of hydrogen sulfide in the pathology of inflammation. Scientifica (Cairo) 2012:159680 doi:doi:10.6064/2012/159680

7. Blacher J, Guerin AP, Pannier B, Marchais SJ, London GM (2001) Arterial calcifications, arterial stiffness, and cardiovascular risk in end-stage renal disease. Hypertension 38:938-942 doi:10.1161/hy1001.096358

8. Cai MM, Wigg B, Smith ER, Hewitson TD, McMahon LP, Holt SG (2015) Relative abundance of fetuin- $A$ in peritoneal dialysis effluent and its association with in situ formation of calciprotein particles: an observational pilot study. Nephrology (Carlton) 20:6-10 doi:10.1111/nep.12350

9. Calvert JW, Jha S, Gundewar S, Elrod JW, Ramachandran A, Pattillo CB, Kevil CG, Lefer DJ (2009) Hydrogen sulfide mediates cardioprotection through Nrf2 signaling. Circ Res 105:365-374 doi:10.1161/CIRCRESAHA.109.199919

10. Fu M, Zhang W, Wu L, Yang G, Li H, Wang R (2012) Hydrogen sulfide (H2S) metabolism in mitochondria and its regulatory role in energy production. Proc Natl Acad Sci U S A 109:2943-2948 doi:10.1073/pnas.1115634109

11. Furne J, Saeed A, Levitt MD (2008) Whole tissue hydrogen sulfide concentrations are orders of magnitude lower than presently accepted values. Am J Physiol Regul Integr Comp Physiol 295:R1479-1485 doi:10.1152/ajpregu.90566.2008

12. Ganster F, Burban M, de la Bourdonnaye M, Fizanne L, Douay O, Loufrani L, Mercat A, Cales P, Radermacher P, Henrion D, Asfar P, Meziani F (2010) Effects of hydrogen sulfide on hemodynamics, inflammatory response and oxidative stress during resuscitated hemorrhagic shock in rats. Crit Care 14:R165 doi:10.1186/cc9257

13. Geng B, Chang L, Pan C, Qi Y, Zhao J, Pang Y, Du J, Tang C (2004) Endogenous hydrogen sulfide regulation of myocardial injury induced by isoproterenol. Biochem Biophys Res Commun 318:756-763 doi:10.1016/j.bbrc.2004.04.094 
14. Giachelli CM (2004) Vascular calcification mechanisms. J Am Soc Nephrol. 15:29592964 doi:10.1097/01.ASN.0000145894.57533.C4

15. Gorriz JL, Molina P, Cerveron MJ, Vila R, Bover J, Nieto J, Barril G, Martinez-Castelao A, Fernandez E, Escudero V, Pinera C, Adragao T, Navarro-Gonzalez JF, Molinero LM, Castro-Alonso C, Pallardo LM, Jamal SA (2015) Vascular calcification in patients with nondialysis CKD over 3 years. Clin J Am Soc Nephrol 10:654-666 doi:10.2215/CJN.07450714

16. Han W, Dong Z, Dimitropoulou C, Su Y (2011) Hydrogen sulfide ameliorates tobacco smoke-induced oxidative stress and emphysema in mice. Antioxid Redox Signal 15:2121-2134 doi:10.1089/ars.2010.3821

17. Heiss A, Eckert T, Aretz A, Richtering W, van Dorp W, Schafer C, Jahnen-Dechent W (2008) Hierarchical role of fetuin-A and acidic serum proteins in the formation and stabilization of calcium phosphate particles. J Biol Chem 283:14815-14825 doi:10.1074/jbc.M709938200

18. Itoh K, Mimura J, Yamamoto M (2010) Discovery of the negative regulator of Nrf2, Keap1: a historical overview. Antioxid Redox Signal 13:1665-1678 doi:10.1089/ars.2010.3222

19. Jaiswal AK (2004) Nrf2 signaling in coordinated activation of antioxidant gene expression. Free Radic Biol Med 36:1199-1207 doi:10.1016/j.freeradbiomed.2004.02.074

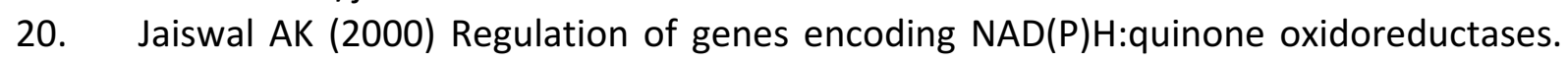
Free Radic Biol Med 29:254-262 doi:10.1016/S0891-5849(00)00306-3

21. Kimura $Y$, Goto $Y$, Kimura $\mathrm{H}$ (2010) Hydrogen sulfide increases glutathione production and suppresses oxidative stress in mitochondria. Antioxid Redox Signal 12:1-13 doi:10.1089/ars.2008.2282

22. Knight EL, Rimm EB, Pai JK, Rexrode KM, Cannuscio CC, Manson JE, Stampfer MJ, Curhan GC (2004) Kidney dysfunction, inflammation, and coronary events: a prospective study. J Am Soc Nephrol 15:1897-1903 doi:10.1097/01.ASN.0000128966.55133.69

23. Kobayashi A, Kang MI, Watai Y, Tong KI, Shibata T, Uchida K, Yamamoto M (2006) Oxidative and electrophilic stresses activate Nrf2 through inhibition of ubiquitination activity of Keap1. Mol Cell Biol 26:221-229 doi:10.1128/MCB.26.1.221-229.2006

24. Kobayashi M, Yamamoto M (2005) Molecular mechanisms activating the Nrf2-Keap1 pathway of antioxidant gene regulation. Antioxid Redox Signal 7:385-394 doi:10.1089/ars.2005.7.385

25. Kolluru GK, Shen X, Bir SC, Kevil CG (2013) Hydrogen sulfide chemical biology: pathophysiological roles and detection. Nitric Oxide 35:5-20 doi:10.1016/j.niox.2013.07.002

26. Luo G, Ducy P, McKee MD, Pinero GJ, Loyer E, Behringer RR, Karsenty G (1997) Spontaneous calcification of arteries and cartilage in mice lacking matrix GLA protein. Nature 386:78-81 doi:org/10.1038/386078a0

27. Nishida M, Kumagai Y, Ihara H, Fujii S, Motohashi H, Akaike T (2016) Redox signaling regulated by electrophiles and reactive sulfur species. J Clin Biochem Nutr 58:91-98 doi:10.3164/jcbn.15-111

28. Olson KR, Deleon ER, Gao Y, Hurley K, Sadauskas V, Batz C, Stoy GF (2013) Thiosulfate: a readily accessible source of hydrogen sulfide in oxygen sensing. Am J Physiol Regul Integr Comp Physiol 305:R592-603 doi:10.1152/ajpregu.00421.2012 
29. Olson KR, DeLeon ER, Liu F (2014) Controversies and conundrums in hydrogen sulfide biology. Nitric Oxide 41:11-26 doi:10.1016/j.niox.2014.05.012

30. Olson KR, Dombkowski RA, Russell MJ, Doellman MM, Head SK, Whitfield NL, Madden JA (2006) Hydrogen sulfide as an oxygen sensor/transducer in vertebrate hypoxic vasoconstriction and hypoxic vasodilation. J Exp Biol 209:4011-4023 doi:10.1242/jeb.02480

31. Pasch A, Schaffner T, Huynh-Do U, Frey BM, Frey FJ, Farese S (2008) Sodium thiosulfate prevents vascular calcifications in uremic rats. Kidney Int 74:1444-1453 doi:10.1038/ki.2008.455

32. Perna AF, Luciano MG, Ingrosso D, Pulzella P, Sepe I, Lanza D, Violetti E, Capasso R, Lombardi C, De Santo NG (2009) Hydrogen sulphide-generating pathways in haemodialysis patients: a study on relevant metabolites and transcriptional regulation of genes encoding for key enzymes. Nephrol Dial Transplant 24:3756-3763 doi:10.1093/ndt/gfp378

33. Reynolds JL, Joannides AJ, Skepper JN, McNair R, Schurgers L, Proudfoot D, JahnenDechent W, Weissberg PL, Shanahan CM (2004) Human vascular smooth muscle cells undergo vesicle-mediated calcification in response to changes in extracellular calcium and phosphate concentrations: a potential mechanism for accelerated vascular calcification in ESRD. J Am Soc Nephrol 15:2857-2867 doi:10.1097/01.ASN.0000141960.01035.28

34. Sage AP, Lu J, Tintut Y, Demer LL (2011) Hyperphosphatemia-induced nanocrystals upregulate the expression of bone morphogenetic protein- 2 and osteopontin genes in mouse smooth muscle cells in vitro. Kidney Int 79:414-422 doi:10.1038/ki.2010.390

35. Smith ER, Cai MM, McMahon LP, Pedagogos E, Toussaint ND, Brumby C, Holt SG (2013) Serum fetuin-A concentration and fetuin-A-containing calciprotein particles in patients with chronic inflammatory disease and renal failure. Nephrology (Carlton) 18:215-221 doi:10.1111/nep.12021

36. Stenvinkel $P$, Ketteler $M$, Johnson RJ, Lindholm B, Pecoits-Filho R, Riella $M$, Heimburger O, Cederholm T, Girndt M (2005) IL-10, IL-6, and TNF-alpha: central factors in the altered cytokine network of uremia--the good, the bad, and the ugly. Kidney Int 67:1216-1233 doi:10.1111/j.1523-1755.2005.00200.x

37. Tanigawa S, Fujii M, Hou DX (2007) Action of Nrf2 and Keap1 in ARE-mediated NQO1 expression by quercetin. Free Radic Biol Med 42:1690-1703 doi:10.1016/j.freeradbiomed.2007.02.017

38. Wallace JL, Wang R (2015) Hydrogen sulfide-based therapeutics: exploiting a unique but ubiquitous gasotransmitter. Nat Rev Drug Discov 14:329-345

39. Wang R (2002) Two's company, three's a crowd: can H2S be the third endogenous gaseous transmitter? FASEB J 16:1792-1798 doi:10.1096/fj.02-0211hyp

40. Wu SY, Pan CS, Geng B, Zhao J, Yu F, Pang YZ, Tang CS, Qi YF (2006) Hydrogen sulfide ameliorates vascular calcification induced by vitamin D3 plus nicotine in rats. Acta Pharmacol Sin 27:299-306 doi:10.1111/j.1745-7254.2006.00283.x

41. Xu ZS, Wang XY, Xiao DM, Hu LF, Lu M, Wu ZY, Bian JS (2011) Hydrogen sulfide protects MC3T3-E1 osteoblastic cells against H2O2-induced oxidative damageimplications for the treatment of osteoporosis. Free Radic Biol Med 50:1314-1323 doi:10.1016/j.freeradbiomed.2011.02.016 
42. Yang G, Zhao K, Ju Y, Mani S, Cao Q, Puukila S, Khaper N, Wu L, Wang R (2013) Hydrogen sulfide protects against cellular senescence via S-sulfhydration of Keap1 and activation of Nrf2. Antioxid Redox Signal 18:1906-1919 doi:10.1089/ars.2012.4645

43. Zavaczki E, Jeney V, Agarwal A, Zarjou A, Oros M, Katko M, Varga Z, Balla G, Balla J (2011) Hydrogen sulfide inhibits the calcification and osteoblastic differentiation of vascular smooth muscle cells. Kidney Int 80:731-739 doi:10.1038/ki.2011.212

44. Zhang DD, Hannink M (2003) Distinct cysteine residues in Keap1 are required for Keap1-dependent ubiquitination of Nrf2 and for stabilization of Nrf2 by chemopreventive agents and oxidative stress. Mol Cell Biol 23:8137-8151 doi:10.1128/MCB.23.22.8137-8151.2003

45. Zhang P, Li Y, Du Y, Li G, Wang L, Zhou F (2016) Resveratrol Ameliorated Vascular Calcification by Regulating Sirt-1 and Nrf2. Transplant Proc 48:3378-3386 doi:10.1016/j.transproceed.2016.10.023

46. Zhao W, Zhang J, Lu Y, Wang R (2001) The vasorelaxant effect of $H(2) S$ as a novel endogenous gaseous K(ATP) channel opener. EMBO J 20:6008-6016 doi:10.1093/emboj/20.21.6008

47. Zhao WH, Gou BD, Zhang TL, Wang K (2012) Lanthanum chloride bidirectionally influences calcification in bovine vascular smooth muscle cells. J Cell Biochem 113:1776-1786 doi:10.1002/jcb.24049 
Figure 1. $\mathrm{H}_{2} \mathrm{~S}$ attenuates calcification of Vascular Smooth Muscle Cells in a concentration dependent manner. A, VSMC were cultured in growth medium supplemented with sec.CPP $(50 \mu \mathrm{g} / \mathrm{mL}$ calcium) and progressively increasing concentrations of NaHS in order to study the concentration-dependence of calcification prevention (Alizarin Red staining was performed for visualisation of calcification $24 \mathrm{hrs}$ later). B, Quantification of calcium deposition. C, Cell viability $24 \mathrm{hrs}$ after treatment with sec.CPP and NaHS was measured using the MTT viability test (mean $\pm \mathrm{SD} ; \mathrm{N}=3 ;{ }^{* * *} p<0.001$ ).

Figure 2. Sulfide ameliorates oxidative stress and inflammation in VSMC. A, Volcano plot of significant and non-significant differentially expressed genes upon treatment (red or blue colors indicate the up- and down-regulated genes, respectively) B, Heatmap representation of significantly expressed genes of sec.CPP + NaHS vs. sec.CPP alone. C, Significantly enriched gene ontology (GO) terms associated with dysregulated genes upon NaHS treatment (enrichment scores equal or higher than three are considered statistically significant). D, Gene network analysis to explore the possible interactions among the significantly expressed genes and selected cellular processes (cellular responses to oxidative stress or inflammation). E, NGS data validation of selected candidate genes using qRT-PCR. F, Exposure of VSMC to sec.CPP in vitro significantly increased $\mathrm{H}_{2} \mathrm{O}_{2}$ generation, which was profoundly reduced by concomitant NaHS treatment (mean $\pm \mathrm{SD} ; \mathrm{N}=3 ;{ }^{*} p<0.05$ ).

Figure 3. NQO1 mediates the inhibitory effects of NaHS on VSMC calcification. A, VSMC and sec.CPP were incubated in the presence or absence of $300 \mu \mathrm{mol} / \mathrm{L}$ NaHS for 24 hrs. NQO1 was determined by RT-PCR and Western blot analysis. B, NaHS stimulates NQO1 mRNA and protein expression in a concentration-dependent manner in the absence of sec.CPP. C, VSMC were treated with siNQO1 or siCtrl and incubated with secondary CPP + NaHS for 24 hrs. Significant down-regulation of NQO1 was confirmed by RT-PCR and Western blot analysis. D, The inhibitory effect of NaHS on calcification is blunted by NQO1 gene knockdown. Calcification was visualized by Alizarin Red staining, and confirmed by $\mathbf{E}$, Quantification of calcium deposition (mean $\pm \mathrm{SD} ; \mathrm{N}=3 ;{ }^{* *} p<0.01$ ).

Figure 4. NaHS acts via modulating KEAP1- and NRF2-regulated NQO1 gene expression. A, Effects of NaHS on KEAP1 and NRF2 expression, determined by RT-PCR and Western blot analysis. GAPDH was used as internal control. B, Gene silencing with specific siRNA. After 24 hrs, cells were treated with a combination of sec.CPP and 300 $\mu \mathrm{mol} / \mathrm{L}$ NaHS, and the resulting mRNA levels were determined by RT-PCR. C, Western blot analysis of KEAP1, NRF2 and NQO1 protein levels. Data are representative of three independent experiments. D, Effect of KEAP1 and NRF2 silencing on calcification inhibition by sulfide. Calcification was visualized by Alizarin Red staining and E, Quantification of calcium deposition (mean $\pm \mathrm{SD} ; \mathrm{N}=3 ;{ }^{*} p<0.05,{ }^{* *} p<0.01,{ }^{* * *} p<0.001,{ }^{* * * *} p<0.0001$ ).

Figure 5. Translocation of NRF2 from cytoplasm to nucleus upon treatment of VSMC with NaHS. A, VSMC were cultured on glass chamber slides, incubated in the presence or absence of $300 \mu \mathrm{mol} / \mathrm{L} \mathrm{NaHS}$ and analyzed using immunofluorescence microscopy using a specific primary antibody against NRF2 (background staining without primary antibody). B. Cytoplasmic and nuclear fractions (Nucleic-acid-binding proteins (NABP), insoluble nuclear proteins) were analyzed by Western Blot with antibodies directed against NRF2, Tubulin (cytoplasmic marker) and Fibrillarin (nuclear marker). C, Schematic illustration of VSMC calcification and its prevention by $\mathrm{H}_{2} \mathrm{~S}_{\text {HS }}{ }^{-}$via KEAP1/NRF2/NQO1 activation. 
(A)

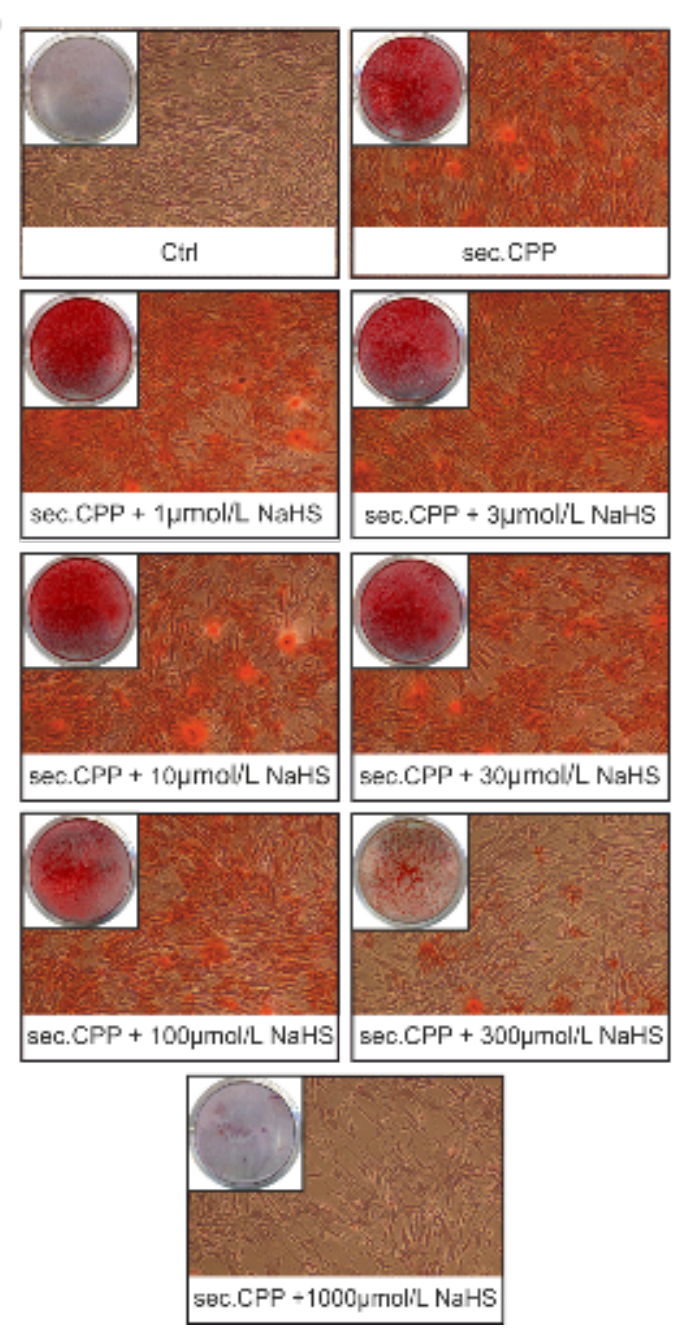

(B)

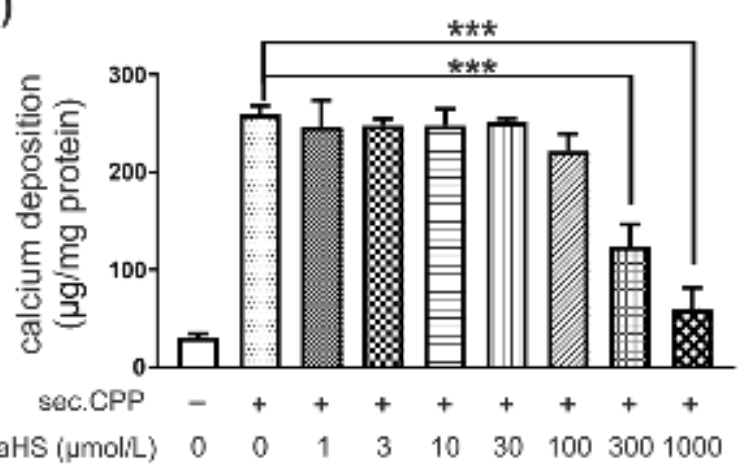

(C)

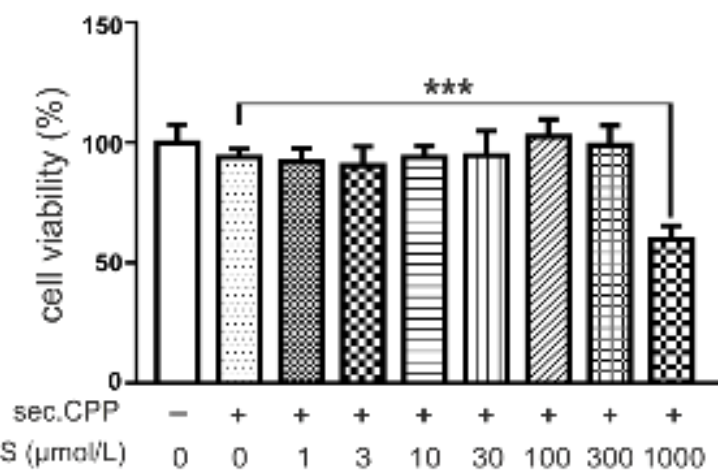


(A)

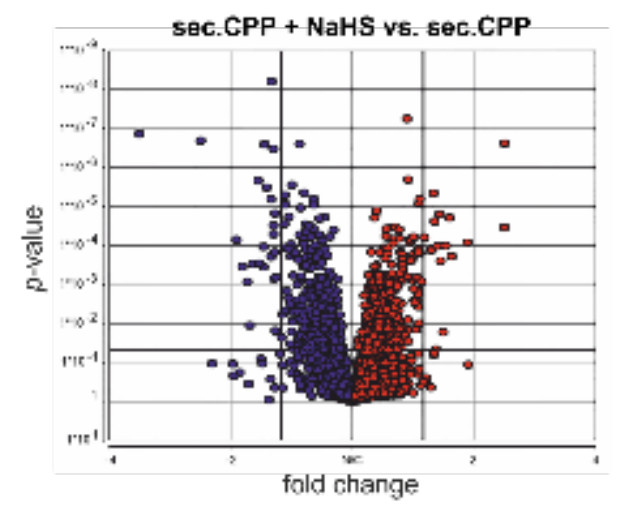

(B)

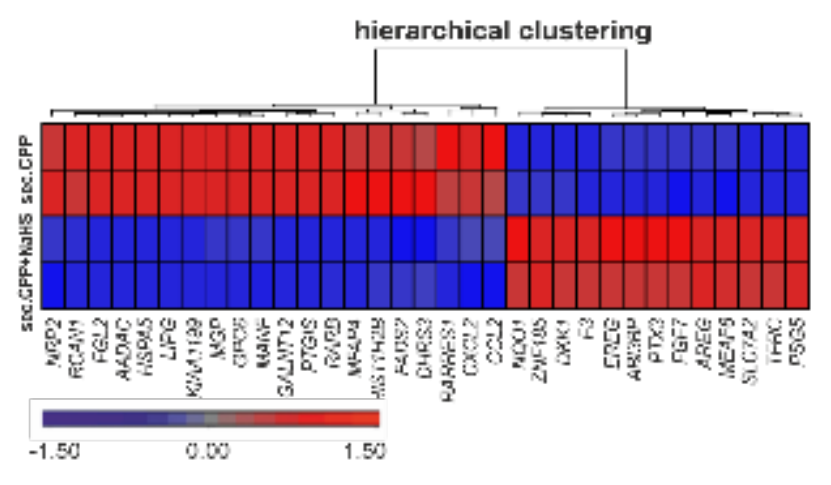

(C)

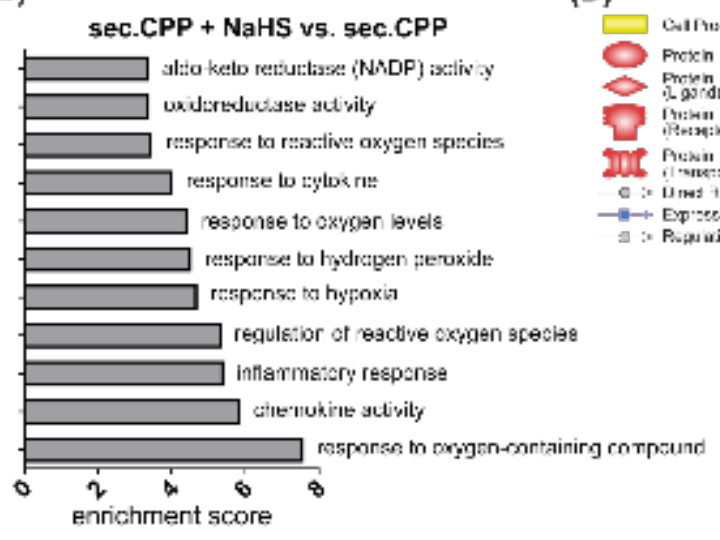

(E)

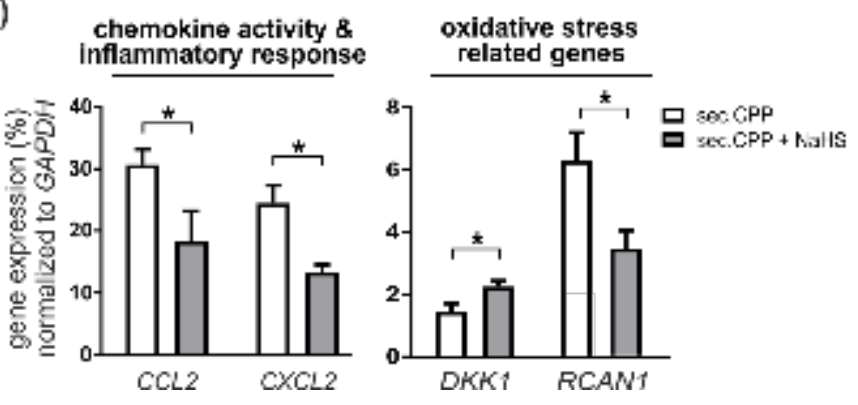

(D)

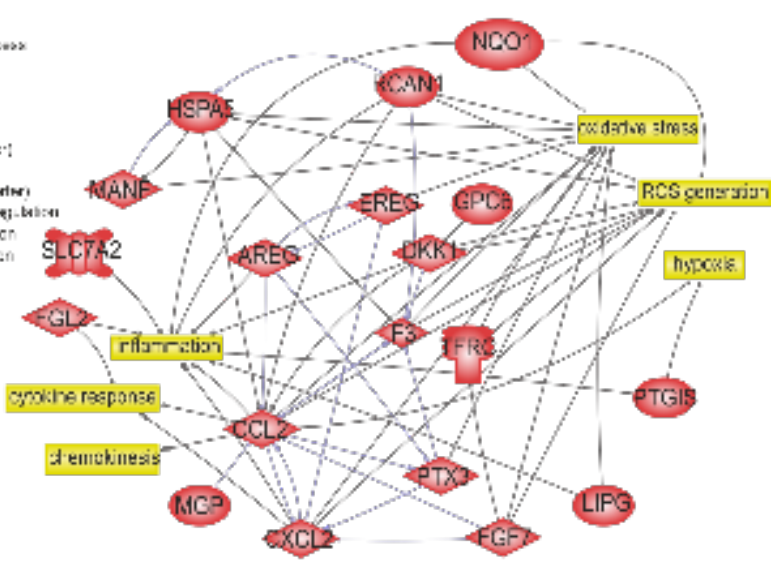

(F)

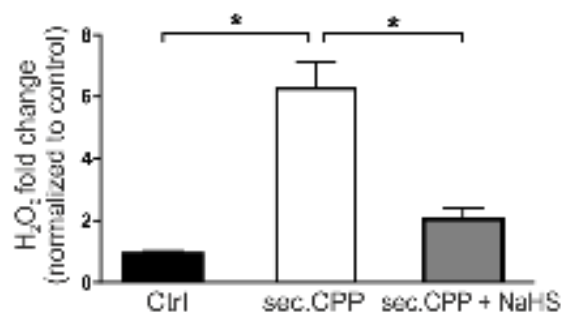


(A)
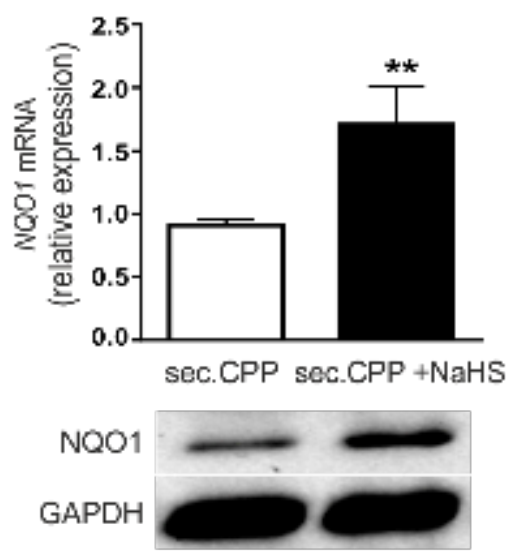

(C)

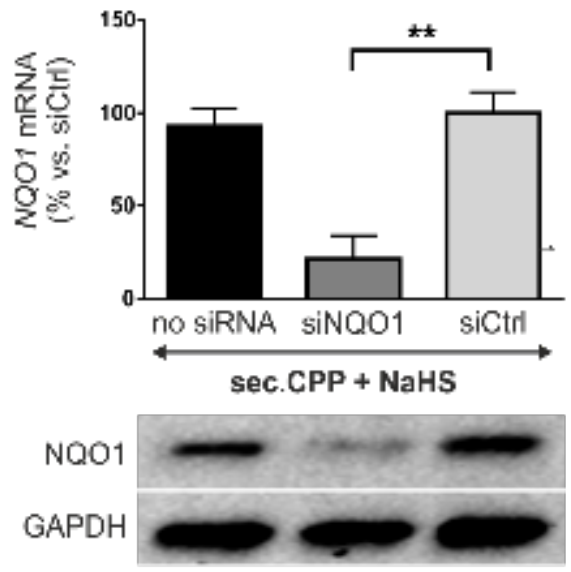

(B)

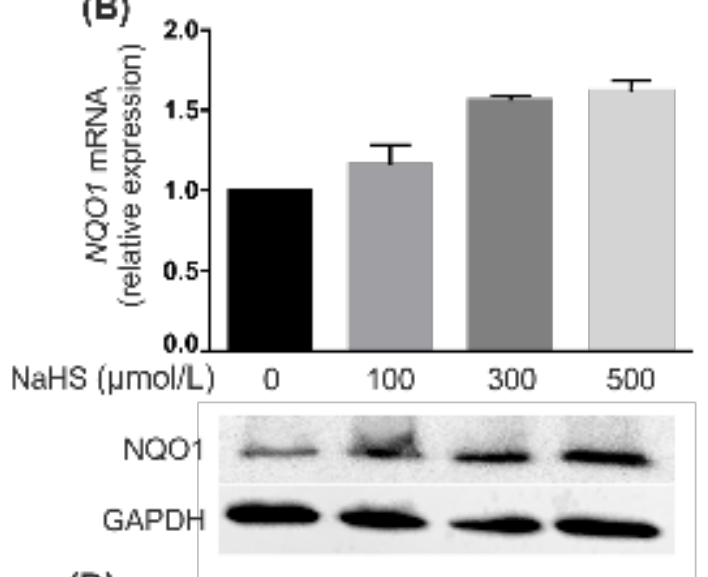

(D)

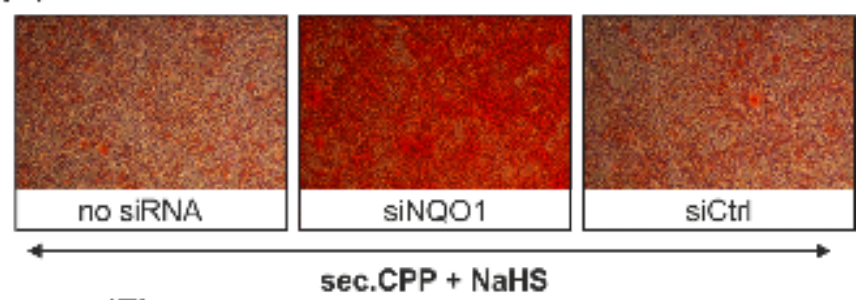

(E)

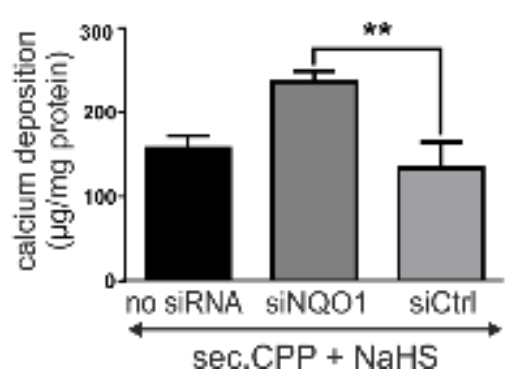


(A)

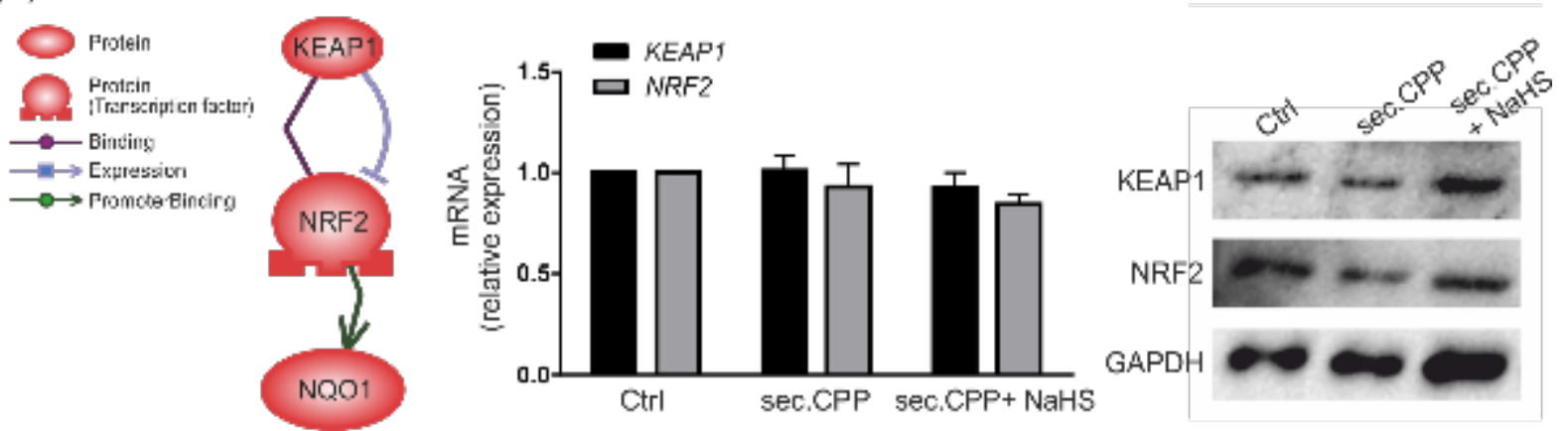

(B)

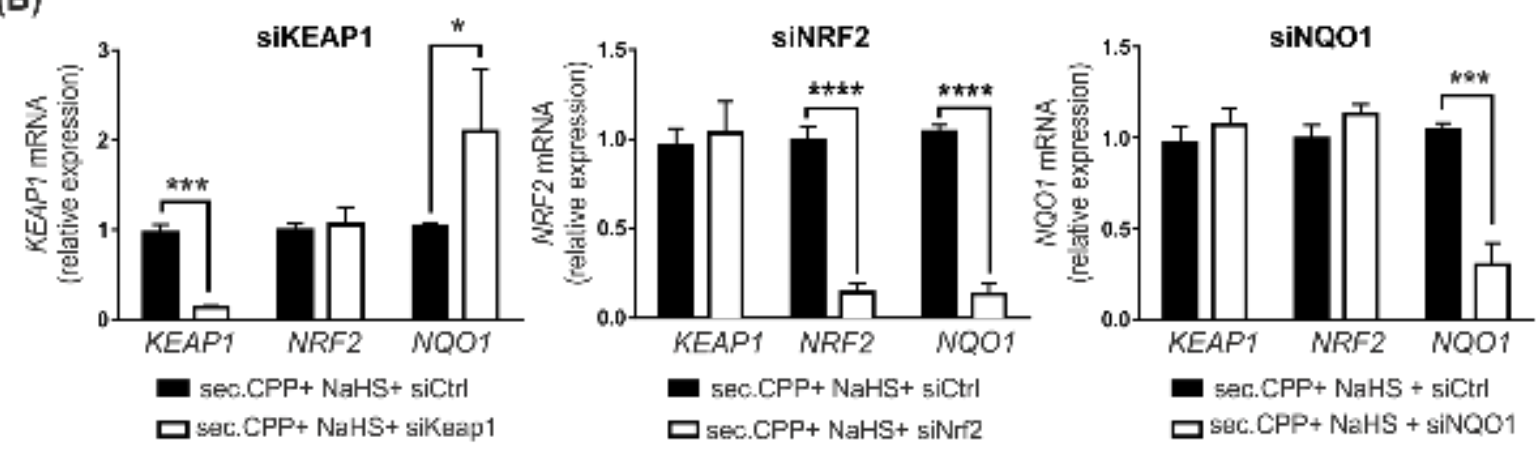

(C)

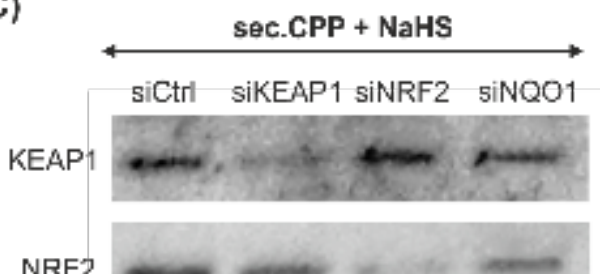

NQO1

$\mathrm{GAPDH}$
(D)

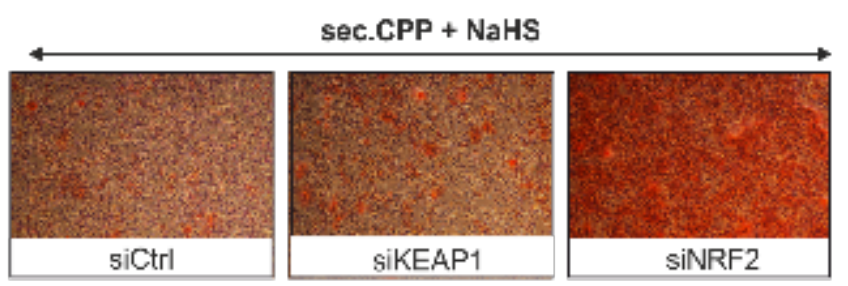

(E)

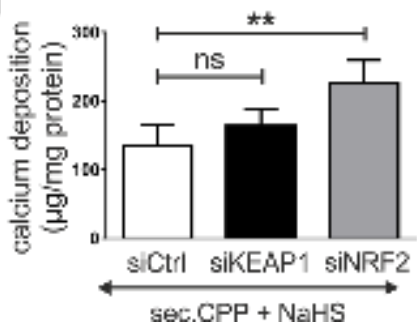


(A)

background staining
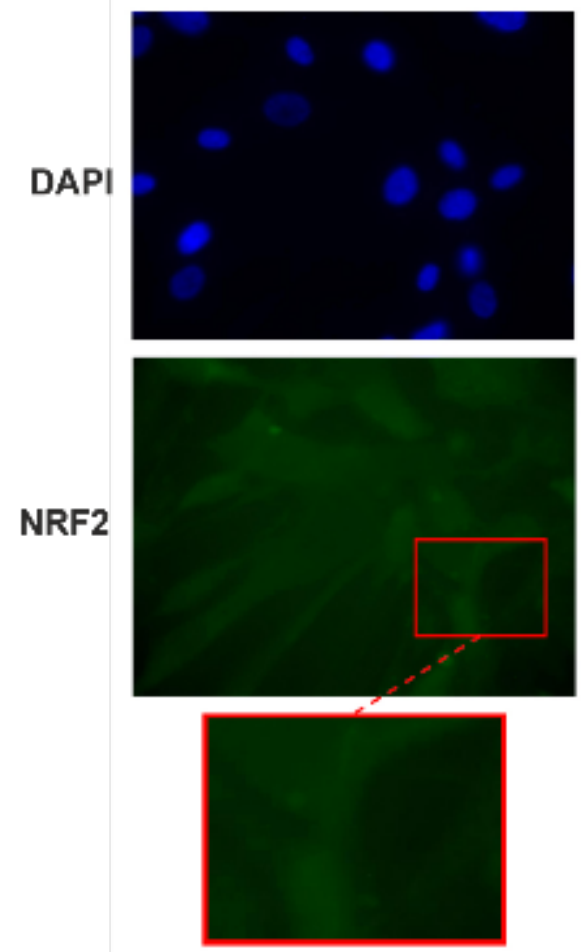

before NaHS
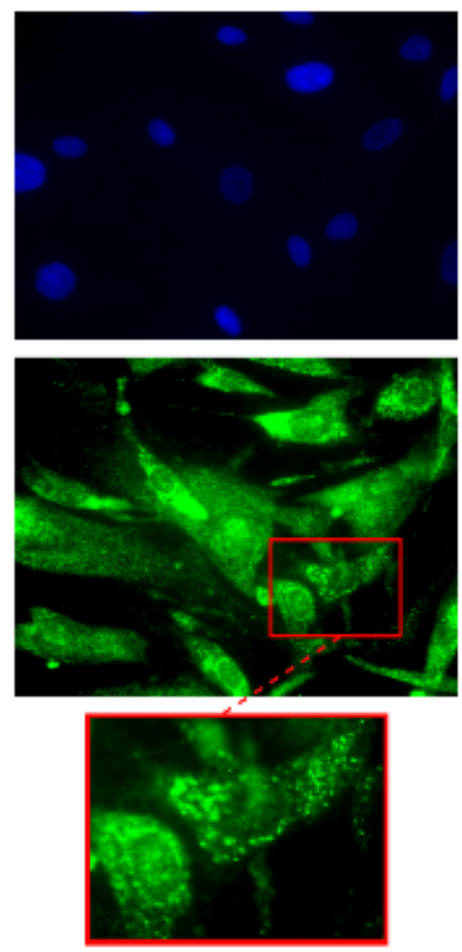

after NaHS
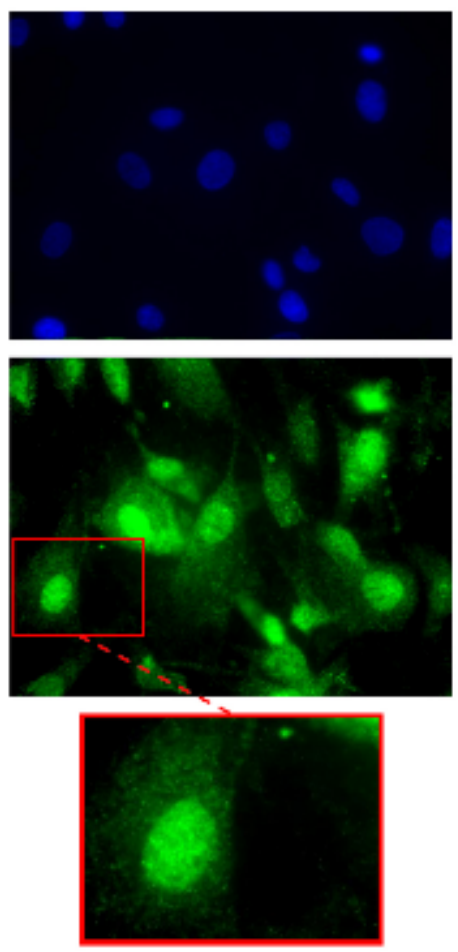

(B)

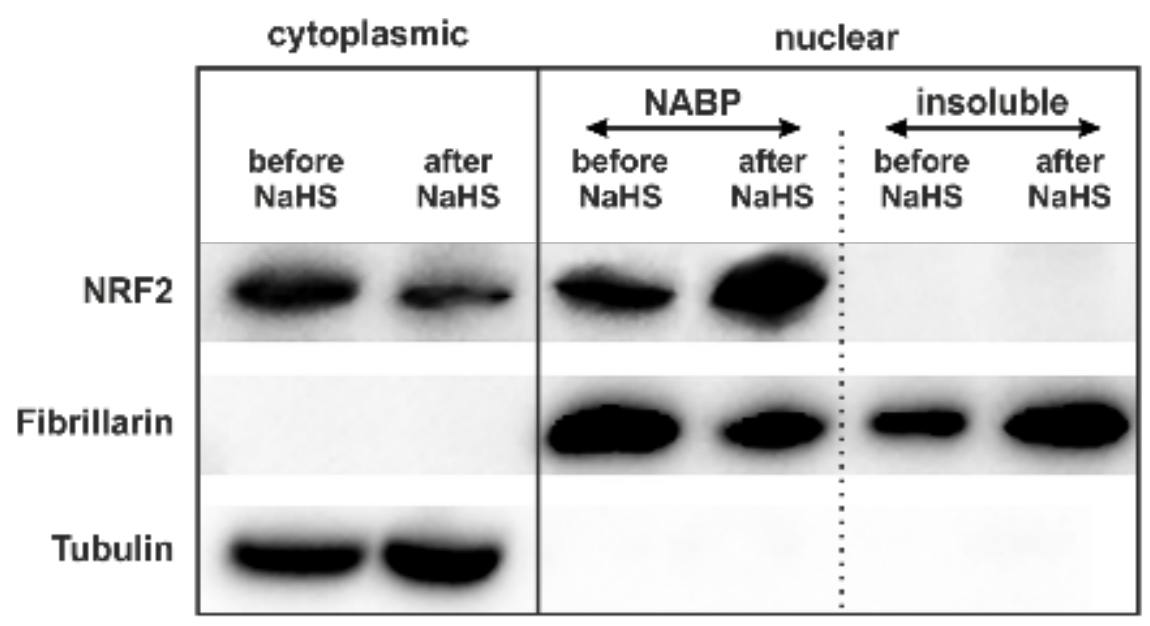

(C)

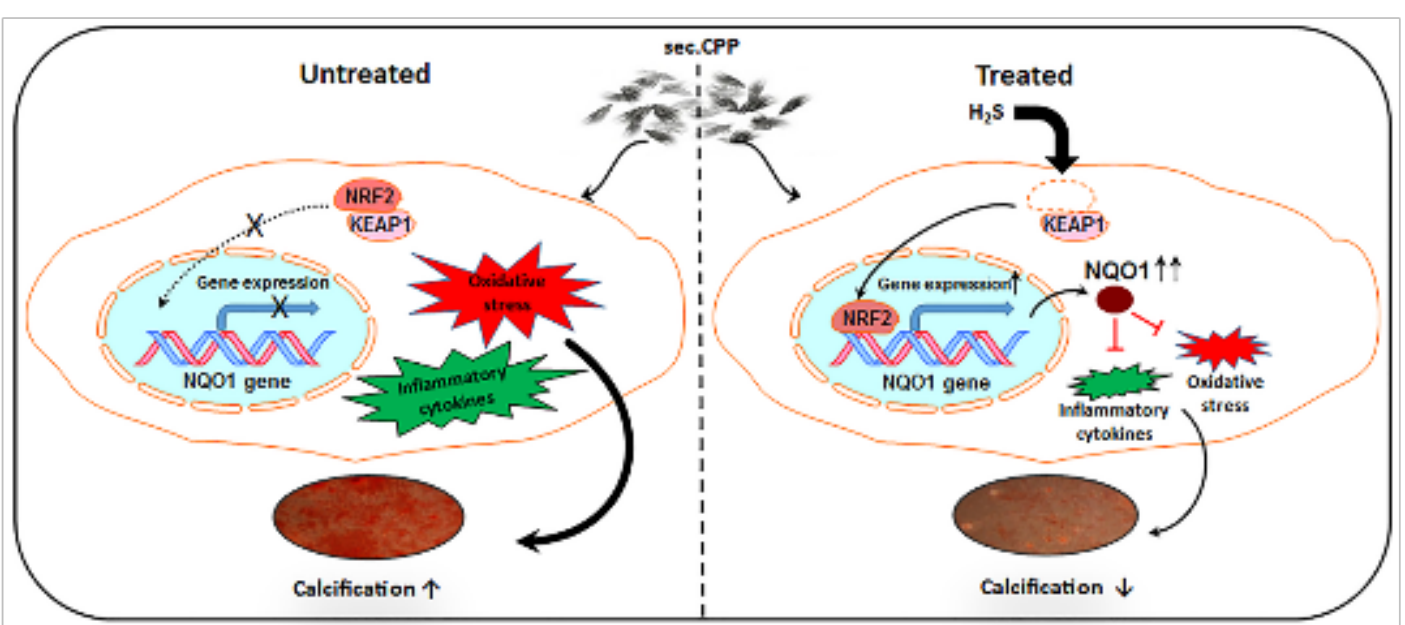




\title{
Supplementary Data
}

\section{Hydrogen Sulfide Attenuates Calcification of Vascular Smooth Muscle Cells via KEAP1/NRF2/NQO1 Activation}

\author{
Parisa Aghagolzadeh ${ }^{1,6}$, Ramin Radpour ${ }^{1}$, Matthias Bachtler ${ }^{1,6}$, Harry van Goor ${ }^{2}$, \\ Edward R. Smith ${ }^{3}$, Adam Lister ${ }^{4,6}$, Alex Odermatt ${ }^{4,6}$, Martin Feelisch ${ }^{5}$, Andreas \\ Pasch $^{1,6}$
}

\footnotetext{
${ }^{1}$ Department of Clinical Research, University of Bern, Switzerland

${ }^{2}$ Pathology and Medical Biology, University Medical Center Groningen and University of Groningen, the Netherlands

${ }^{3}$ Department of Nephrology, The Royal Melbourne Hospital, Melbourne, Victoria, Australia

${ }^{4}$ Division of Molecular \& Systems Toxicology, Department of Pharmaceutical Sciences, University of Basel, Basel, Switzerland

${ }^{5}$ Clinical and Experimental Sciences, Faculty of Medicine, Southampton General Hospital and Institute for Life Sciences, University of Southampton, Southampton, UK

${ }^{6}$ The National Centre of Competence in Research (NCCR) "Kidney.CH - Kidney Control of Homeostasis", Switzerland
}

Running title: Sulfide attenuates vascular calcification

*Address for correspondence:

Dr. Andreas Pasch, MD

Department of Clinical Research

University of Bern

3010 Bern, Switzerland

Phone: +4131632 3037

E-mail: andreas.pasch@dkf.unibe.ch 


\section{Methods}

\section{Cell Culture}

Primary Human Aortic Smooth Muscle Cells (VSMC) were purchased (PCS-100-012, ATCC, USA). Cells were cultured under sterile conditions in vascular cell basal medium (PCS-100030, ATCC) supplemented with VSMC growth kit components comprising insulin, ascorbate, L-glutamine, recombinant human EGF and FGFß, and fetal bovine serum (FBS) (PCS-100042, ATCC) in the presence of antibiotics (Penicillin-Streptomycin). Cells were used from passages three to five.

\section{Induction of calcification and quantification of calcium deposition}

VSMC calcification was induced as previously described. Briefly, secondary CPP were generated by adding 10\% FBS, $3.5 \mathrm{mmol} / \mathrm{L}$ inorganic phosphate, $1 \mathrm{mmol} / \mathrm{L}$ calcium to phenol-free DMEM. This calcification medium was stored at $37^{\circ} \mathrm{C}$ for 6 days to generate secondary CPP. The presence of secondary CPP was confirmed using transmission electron microscopy (TEM). The particle-containing calcification media were centrifuged at $25,000 \times \mathrm{g}$ for 120 minutes at $4^{\circ} \mathrm{C}$ and the calcium content of CPP was determined. Complete VSMC culture medium supplemented with secondary CPP (to a final concentration of $50 \mu \mathrm{g} / \mathrm{mL}$ calcium) was used to trigger calcification. VSMC were cultured with the calcification medium for 24 hours and mineralization was assessed qualitatively by staining with Alizarin Red S, and quantitatively by measurement of cell-associated calcium using the QuantiChrome calcium assay kit (Socochim, Switzerland) and normalized to cellular protein content.

\section{NaHS treatment of VSMC}

To find the threshold concentration as well as analyzing the impact of sulfide on calcification prevention, VSMC were exposed to control growth medium without CPP, growth medium supplemented with secondary CPP (final concentration equivalent to $50 \mu \mathrm{g} / \mathrm{mL}$ calcium) or growth medium supplemented concurrently with secondary CPP and various concentrations of freshly prepared solutions of sodium hydrosulfide (NaHS nonahydrate; 1, 3, 10, 30, 100, 300 and $1000 \mu \mathrm{mol} / \mathrm{L})$ (Sigma, Switzerland) for $24 \mathrm{~h}$.

\section{Cell viability}

Cell viability was determined using MTT [3-(4,5-dime-thylthiazolyl-2)-2,5-diphenyltetrazolium

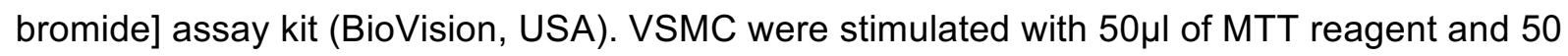
$\mu \mathrm{l}$ of serum-free media and incubated at $37^{\circ} \mathrm{C}$ for $3 \mathrm{hrs}$. After incubation, $150 \mu \mathrm{l}$ of MTT solvent was added into each well. Absorbance at $570 \mathrm{~nm}$ was measured with multi-well 
spectrophotometer (ELISA reader). Cell viability was assessed by calculating percentage differences in absorbance compared to control.

\section{High-throughput transcriptome analysis using next generation sequencing (NGS)}

Total RNA was extracted from VSMC lysates using the RNeasy Micro Kit (QIAGEN AG, Switzerland) according to the manufacturer's instructions. Total RNA quality was determined by a Bioanalyzer (Agilent Technologies, USA) using the RNA 6000 Nano Chip (Agilent Technologies) and quantified by fluorometry using the Quantus Fluorometer Instrument (Promega, USA) with the kit Quantifluor RNA System (Promega). Library preparation was performed with $650 \mathrm{ng}$ of total RNA using the TruSeq Stranded mRNA Library Prep Kit (Illumina, USA). The enriched libraries were quantified by the Fragment Analyzer (Advanced Analytical, USA) using the standard sensitivity NGS fragment analysis kit (Advanced Analytical), which revealed an excellent quality of the libraries (average concentration was $182 \mathrm{nmol} / \mathrm{L}$ and average library size was 349 base pairs). Samples were pooled to achieve equal molarity. Each pool was run on the Fragment Analyzer for a quality-check and for quantification purposes in order to be adjusted to $1.5 \mathrm{pM}$, followed by clustering on the NextSeq 500 instrument (Illumina). RNA-seq samples were sequenced using the NextSeq 500 High Output Kit 75-cycles (Illumina), and primary data analysis was performed with the Illumina Real-Time Analysis (RTA version 2.1.3) and bcl2fastq-2.16.0.10.

\section{RNA-seq data analysis to access differentially expressed genes}

The RNA-seq data was analyzed using the ArrayStar software v.12.2 (DNASTAR, USA). The level of gene expression was assessed after reads per kilobase of target per million reads mapped (RPKM) normalization and log transformation. The data set was analyzed by twoway ANOVA. A volcano plot was generated to illustrate differentially expressed genes of sulfide-treated versus non-treated calcifying VSMC by plotting $p$-value versus fold change on the $y$ and $x$ axes, respectively. Genes with significant difference in their expression at $p<0.05$ and fold differences $\geq 1.5$ were selected. Data were clustered using standard Euclidean's method based on the average linkage. The heatmap was generated according to the standard normal distribution of the values (this standardization treats the mean of each column as zero and scales it to a standard deviation of 1 in order to weigh all columns equally).

\section{Gene ontology enrichment, cell signaling and in silico pathway analysis}

Gene networks and canonical pathways representing differentially expressed genes were identified using the Ariadne Genomics Pathway Studio $®$ software (Elsevier). The gene ontology (GO) enrichment takes a list of significantly expressed genes at different treatment 
conditions and groups them into functional hierarchies. The enrichment scores were calculated using chi-square test comparing the proportion of the gene list to the proportion of the background in the group. If a functional group had an enrichment score over 1 , the functional category was over-expressed. A value of 3 or higher corresponded to a significant over-expression $(p<0.05)$.

In silico pathway analysis predicts potential biological processes, pathways and molecules affected by differentially expressed genes. The data sets containing gene identifiers were uploaded into the Pathway Studio database. The functional analysis identified direct interactions between differentially expressed genes in order to facilitate an understanding beyond their regulatory networks.

\section{Quantitative real-time PCR (qRT-PCR) validation}

Relative transcript expression levels were measured by qRT-PCR using the oligonucleotide primers (Suppl. Table1 lists primer sequences) and SYBR Green PCR Master Mix (Roche, Switzerland). Melt-curve analysis was performed to confirm the presence of single specific products and non-template control runs to assess possible contamination. The GAPDH gene was used to normalize the cDNA concentration of each sample. RT-PCR reactions were performed in three replicates using 96-well plates with the ABI 7500 Fast Real-Time PCR System (Applied Biosystems, USA). Average fold differences were calculated by the comparative $\mathrm{Ct}$ method $\left(2^{-\Delta \Delta \mathrm{Ct}}\right)$ between pairs of samples.

\section{Determination of $\mathrm{H}_{2} \mathrm{O}_{2}$ in cell supernatants}

VSMC were cultured in 24-well plates for 24 hours followed by treatment with secondary CPP or secondary CPP plus $\mathrm{H}_{2} \mathrm{~S}$ for $24 \mathrm{hrs}$. The cell supernatant was centrifuged at $1,000 \mathrm{xg}$ for 15 minutes after the treatment period. Samples were then subjected to ultrafiltration through a $10 \mathrm{kD}$ MWCO spin filter to remove the bulk of proteins. Thereafter, $\mathrm{H}_{2} \mathrm{O}_{2}$ was determined by the horseradish peroxidase mediated oxidation of OxiRed to resorufin using a commercially available assay kit (Biovision, USA).

\section{Protein extraction, detection and quantification}

Protein lysates were prepared by resuspending cell pellets in radio-immunoprecipitation assay (RIPA) buffer. The protein concentration of cell homogenates was determined using the Pierce BCA Protein Assay Kit (Thermo Fisher Scientific, Switzerland). Equal amounts (10 $\mu \mathrm{g}$ ) of samples were subjected to SDS-polyacrylamide ( $10 \%$ acrylamide) gel electrophoresis using a $4 \%$ acrylamide stacking gel, followed by semidry electroblotting onto a nitrocellulose membrane (GE-Healthcare, UK). The membranes were blocked with $5 \%$ non-fat dry milk in TBST buffer (Tris-buffered saline containing $0.1 \%$ Tween-20) for $60 \mathrm{~min}$. Western Blotting 
was performed using primary antibodies against NQO1 (Rabbit polyclonal: 1:1000; Cat No. ab34173; Abcam, Switzerland), NRF2 (NFE2L2) (Rabbit monoclonal: 1:1000; CatNo. ab62352; Abcam), KEAP1 (Goat polyclonal: 1: 1000; Cat No. sc-15246; Santa Cruz, Switzerland); and diluted in TBST with $1 \%$ non-fat dry milk powder. GAPDH (Rabbit polyclonal: 1:1000; Cat No. 14C10; Cell Signaling, Switzerland) was used as a loading control. Primary antibodies were detected using an appropriate horseradish peroxidaseconjugated secondary antibody (HRP conjugated anti-Rabbit IgG, 1: 10000 for GAPDH and NQO1; 1:3000 for NRF2; HRP conjugated anti-Goat IgG, 1:3000 for KEAP1). Proteins were visualized by SuperSignal ${ }^{\mathrm{TM}}$ West Dura Extended Duration Substrate (Thermo Fisher) or ECL Detection Reagents (GE Healthcare).

\section{Nuclear and cytoplasmic extraction}

Three protein fractions (Nucleic-acid-binding proteins such as transcription factors, insoluble nuclear proteins and cytosolic proteins) were isolated using the Qproteome Nuclear Protein Kit (QIAGEN AG) according to the manufacturer's instructions. Western Blotting was performed using primary antibodies against NRF2 (NFE2L2) (Mouse monoclonal: 1:1000; CatNo. ab89443; Abcam). Analysis of Fibrillarin (Rabbit polyclonal: 1:1000; Cat No. ab5821; Abcam) and Tubulin (Rabbit polyclonal: 1:1000; Cat No. ab6046; Abcam) expression were done as a loading control for nuclear and cytoplasmic fraction respectively.

\section{Small interfering RNA (siRNA)-mediated gene silencing}

Commercially available human NQO1, NRF2, KEAP1 siRNA (Santa Cruz Biotechnology, Switzerland) were used according to the manufacturer's instructions with minor modifications to increase silencing efficiency in primary VSMC. Briefly, $5 \mu \mathrm{l}$ of $10 \mu \mathrm{mol} / \mathrm{L}$ siRNA (siNQO1, siNRF2, siKEAP1 or scrambled siRNA as siCtrl) was mixed with $100 \mu$ l siRNA transfection medium and $5 \mu \mathrm{l}$ of Lipofectamine LTX (Invitrogen, Switzerland) in $100 \mu \mathrm{L}$ of serum-free transfection media. Reagents were then incubated for $45 \mathrm{~min}$ at room temperature. Cells were treated with $200 \mu \mathrm{l}$ transfection complexes in the presence of $800 \mu \mathrm{l}$ antibiotic-free growth medium, supplemented with 5\% FBS for 24 hours. Thereafter, cells were exposed to growth medium containing secondary CPP, secondary CPP $+\mathrm{NaHS}$, or medium in the absence of CPP (control). Transfection efficiency was confirmed by RT-PCR and Western blotting.

\section{Immunofluorescence microscopy of NRF2}

Immunofluorescence analysis of NRF2 was performed according to standard protocols. In brief, cells were grown on glass chamber slides (Thermo Fisher Scientific, Switzerland), incubated with or without NaHS (300 $\mu \mathrm{mol} / \mathrm{L})$ for $120 \mathrm{~min}$, fixed with methanol for $10 \mathrm{~min}$, 
washed three times in PBS and then incubated 30 min with $10 \%$ FBS in PBS. Thereafter, cells were incubated with monoclonal anti-NRF2 antibody (1:500; CatNo. ab62352; Abcam, Switzerland) for 1 hour at room temperature, washed three times with PBS and then incubated with the appropriate secondary antibodies for 1 hour (Alexa Fluor ${ }^{\circledR}$ 488conjugated goat anti-rabbit IgG; 1/1000) followed by washing three times in PBS. After incubation with antibodies, nuclear staining was performed using Vectashield mounting medium containing DAPI, and cells were analyzed by immunofluorescence microscopy.

\section{Statistical Analysis}

Statistical analysis was performed using GraphPad Prism software v.7.0 (GraphPad, USA). Data are represented as mean \pm SD. The Shapiro-Wilk test was used to determine whether the data meet the assumption of normality. Gene expression data was analyzed using 1-way ANOVA, Tukey's multiple comparison test and Student's t-test. Non-parametric data was analyzed using Mann Whitney $U$ test. Difference between experimental groups was considered significant when ${ }^{*} p<0.05,{ }^{* *} p<0.01$, and ${ }^{* * *} p<0.001$. 


\section{SUPPLEMENTAL FIGURES AND TABLES}

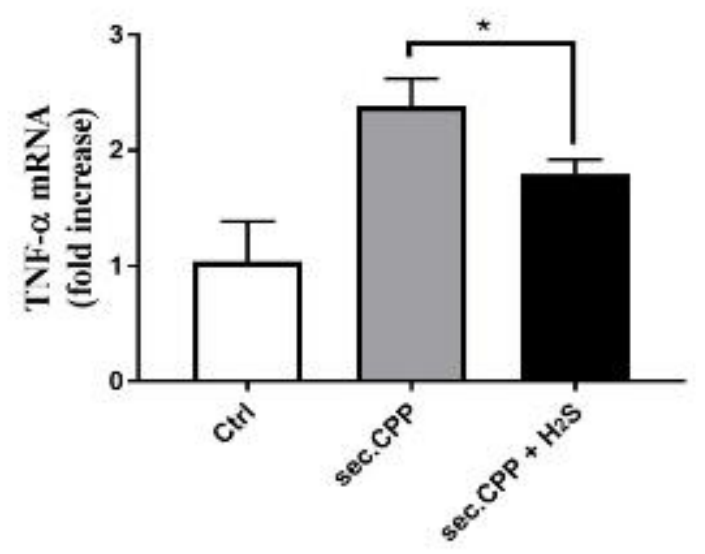

Supplemental Figure 1. Exposure of VSMC to secondary CPP in the presence of NaHS leads to a significant decrease of TNF-a mRNA. VSMC were cultured in 24-well plates followed by treatment with secondary CPP or secondary CPP plus NaHS for $24 \mathrm{hrs}$. Results are mean of three experiments performed in duplicates (mean $\pm \mathrm{SD} ; \mathrm{N}=3 ;{ }^{*} p<0.05$ )

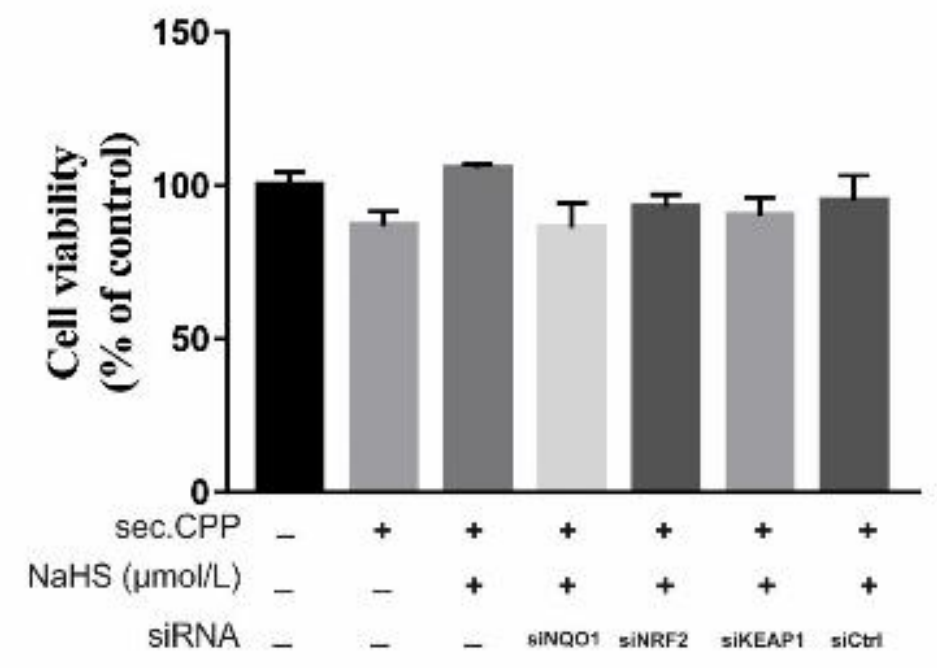

Supplemental Figure 2. Cell viability was not affected by siRNA-mediated gene silencing.

Cell viability was measured using the MTT viability test (mean $\pm S D ; N=3$ ). 


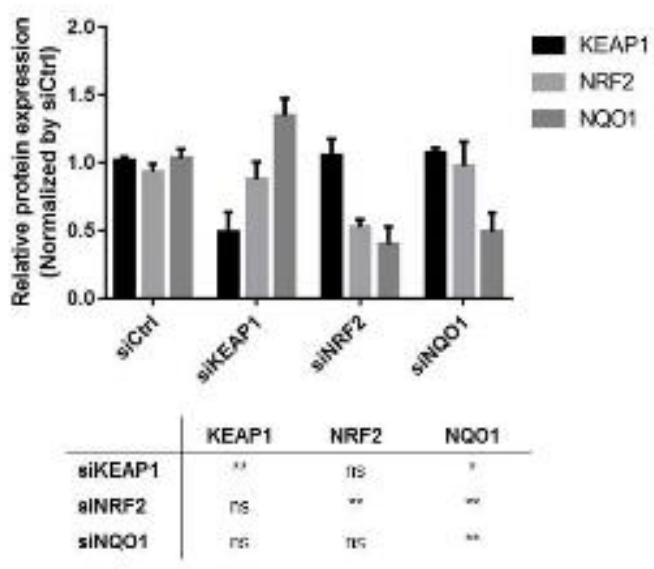

Supplemental Figure 3. Western blot analysis of KEAP1, NRF2 and NQO1 protein levels

(Quantitative data from Fig. 4C.) (mean $\left.\pm S D ; N=3 ;{ }^{* *} p<0.01,{ }^{* *} p<0.001\right)$.

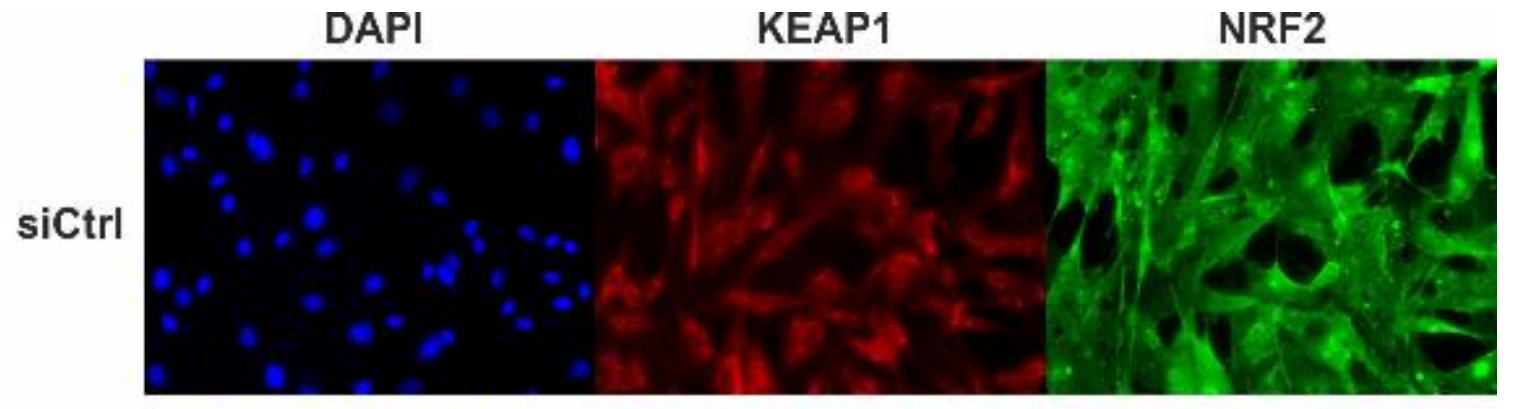

SiKEAP1

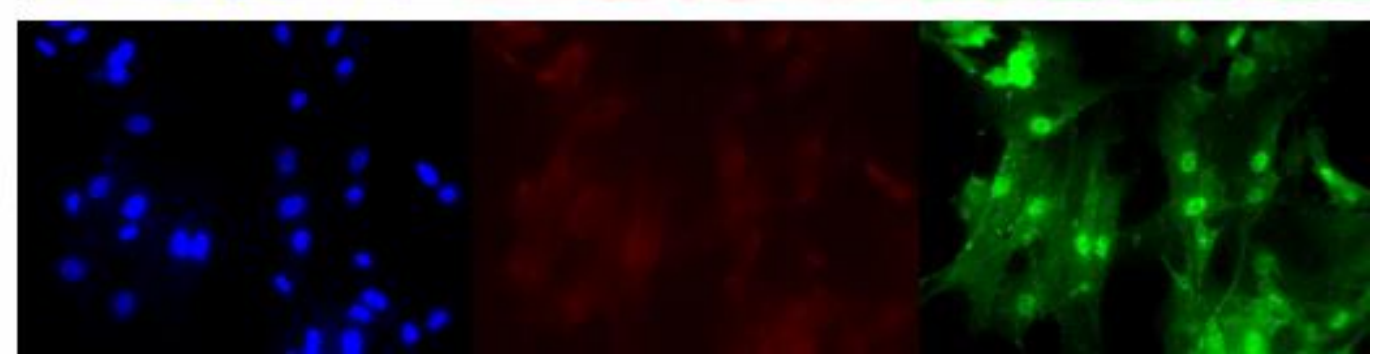

Supplemental Figure 4. Translocation of NRF2 from cytoplasm to nucleus upon silencing of KEAP1. VSMC were cultured on glass chamber slides, followed by gene silencing with specific siRNA against KEAP1 or scramble siRNA (siCtrl) for $24 \mathrm{hrs}$. Cells were analyzed by immunofluorescence microscopy using a specific primary antibody against NRF2 (anti-mouse, Abcam, Switzerland) and KEAP1 (anti-rabbit, Abcam, Switzerland). 

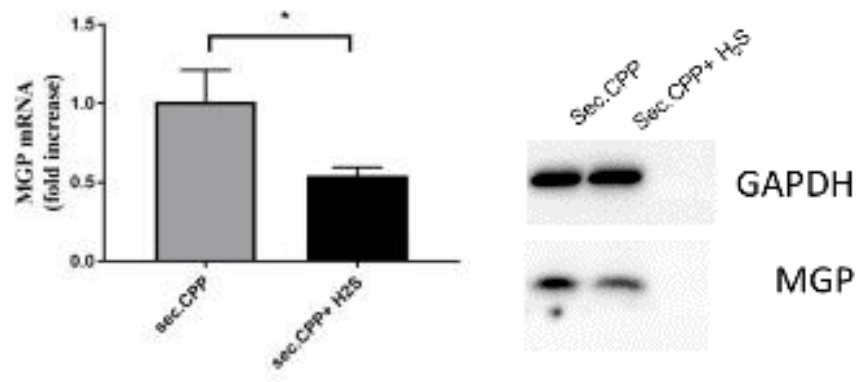

Supplemental Figure 5. VSMC and sec.CPP were incubated in the presence or absence of $300 \mu \mathrm{mol} / \mathrm{L}$ NaHS for $24 \mathrm{hrs}$. MGP was determined by qRT-PCR with the following primers: forward: GAGAGGATCCGAGAACGCT and reverse: TTCCTGAAGTAGCGATTATAGGC. Western Blotting was performed using primary antibodies against MGP (Rabbit polyclonal: 1:1000; Cat No. ab86233; Abcam, Switzerland) and GAPDH (Rabbit polyclonal: 1:1000; Cat No. 14C10; Cell Signaling, Switzerland).

Supplemental Table 1. Primers used for qRT-PCR.

\begin{tabular}{lll}
\hline Gene & Forward & Reverse \\
\hline CCL2 & CTGAGACTAACCCAGAAACATCC & GAATGAAGGTGGCTGCTATGAG \\
CXCL2 & AAACCGAGTCATAGCCACAC & AATAAGCTTCCTCCTTCCTTCTG \\
DKK1 & CGAGGAGAATTGAGGAACCA & CCTTCTTGTCCTTTGGTGTG \\
GAPDH & TCATTTCCTGGTATGACAACGA & CTTCCTCTTGTGCTCTTGCTG \\
KEAP1 & CAACAGTGTGGAGAGGTATGAG & GGCATAAAGGAGACGATTGAGG \\
NQO1 & TCTATGCCATGAACTTCAATCC & TATAAGCCAGAACAGACTCGG \\
NRF2 & CAGCACATCCAGTCAGAAACC & GTAGCCGAAGAAACCTCATTGTC \\
RCAN1 & GAAACCAGGGCCAAATTTGAG & GGGTTGCTGAAGTTTATTCTGAC \\
TNF- $\alpha$ & GCACTTTGGAGTGATCGG & GAGGGTTTGCTACAACATGG \\
\hline
\end{tabular}




\section{Supplemental Table 2. Differentially expressed genes (sec.CPP $+\mathrm{H}_{2} \mathrm{~S}$ vs. sec.CPP)}

\begin{tabular}{|c|c|c|c|c|c|}
\hline Gene symbol & Gene ID & Gene synonym & Gene note & p-value & $\begin{array}{c}\text { Fold change } \\
\text { (sec.CPP+H2S vs. sec.CPP) }\end{array}$ \\
\hline$A A D A C$ & $13,17,600338$ & CES5A1, DAC & arylacetamide deacetylase & 3.31E-07 & -1.56741 \\
\hline$A B / 3 B P$ & $\begin{array}{l}25890,17265,09380 \\
606279\end{array}$ & NESHBP, TARSH & $\begin{array}{l}\mathrm{ABI} \text { family, member } 3(\mathrm{NESH}) \text { binding } \\
\text { protein }\end{array}$ & 0.000249 & 1.6558 \\
\hline AREG & $374,651,00093,104640$ & $A R, C R D G F, S D G F$ & Amphiregulin & 1.91E-05 & 1.74237 \\
\hline CCL2 & $\begin{array}{l}6347,10618,01149 \\
158105\end{array}$ & $\begin{array}{l}\text { GDCF-2, HC11, } \\
\text { HSMCR30, MCAF, } \\
\text { MCP-1, MCP1, } \\
\text { SCYA2, SMC-CF }\end{array}$ & chemokine ( $\mathrm{C}-\mathrm{C}$ motif) ligand 2 & 0.011267 & -1.79353 \\
\hline CXCL2 & $\begin{array}{l}2920,4603,00741 \\
139110\end{array}$ & $\begin{array}{l}\text { CINC-2a, GRO2, } \\
\text { GROb, MGSA-b, MIP- } \\
\text { 2a, MIP2, MIP2A, } \\
\text { SCYB2 }\end{array}$ & chemokine (C-X-C motif) ligand 2 & 0.000293 & -1.70067 \\
\hline DHRS3 & $\begin{array}{l}9249,17693,09915 \\
612830\end{array}$ & $\begin{array}{l}\text { DD83.1, RDH17, } \\
\text { retSDR1, Rsdr1, } \\
\text { SDR1, SDR16C1 }\end{array}$ & $\begin{array}{l}\text { dehydrogenase/reductase (SDR family) } \\
\text { member } 3\end{array}$ & 0.000858 & -1.81808 \\
\hline$D K K 1$ & $\begin{array}{l}22943,2891,05544 \\
605189\end{array}$ & $D K K-1, S K$ & dickkopf WNT signaling pathway inhibitor 1 & 2.42E-05 & 1.60143 \\
\hline EREG & $\begin{array}{l}2069,3443,03638 \\
602061\end{array}$ & $E R$ & Epiregulin & 0.000189 & 1.76578 \\
\hline F3 & $\begin{array}{l}2152,3541,00603 \\
134390\end{array}$ & $C D 142, T F, T F A$ & $\begin{array}{l}\text { coagulation factor III (thromboplastin, tissue } \\
\text { factor) }\end{array}$ & $6.22 \mathrm{E}-05$ & 1.50893 \\
\hline FADS2 & $\begin{array}{l}9415,3575,05854 \\
606149\end{array}$ & $\begin{array}{l}\text { D6D, DES6, FADSD6, } \\
\text { LLCDL2, SLL0262, } \\
\text { TU13 }\end{array}$ & fatty acid desaturase 2 & 0.000108 & -1.65992 \\
\hline FGF7 & $\begin{array}{l}2252,3685,01022 \\
148180\end{array}$ & $H B G F-7, K G F$ & fibroblast growth factor 7 & 0.000104 & 1.62801 \\
\hline FGL2 & $\begin{array}{l}10875,3696,16098 \\
605351\end{array}$ & pT49, T49 & fibrinogen-like 2 & $1.36 \mathrm{E}-07$ & -3.37125 \\
\hline GALNT12 & $79695,19877,610290$ & CRCS1, GalNAc-T12 & $\begin{array}{l}\text { UDP-N-acetyl-alpha-D- } \\
\text { galactosamine:polypeptide N- } \\
\text { acetylgalactosaminyltransferase } 12 \\
\text { (GalNAc-T12) }\end{array}$ & $2.52 \mathrm{E}-07$ & -1.64994 \\
\hline GPC6 & $\begin{array}{l}10082,4454,05099 \\
604404\end{array}$ & OMIMD1 & glypican 6 & $1.52 E-05$ & -1.5518 \\
\hline HIST1H2BK & $\begin{array}{l}85236,13954,13658 \\
615045\end{array}$ & $\begin{array}{l}\text { H2B/S, H2BFAiii, } \\
\text { H2BFT, H2BK }\end{array}$ & histone cluster $1, \mathrm{H} 2 \mathrm{bk}$ & 0.000354 & -1.65781 \\
\hline
\end{tabular}




\begin{tabular}{|c|c|c|c|c|c|}
\hline HSPA5 & $\begin{array}{l}3309,5238,00682 \\
138120\end{array}$ & $\begin{array}{l}\text { BIP, GRP78, HEL-S- } \\
89 n, \text { MIF2 }\end{array}$ & $\begin{array}{l}\text { heat shock } 70 \mathrm{kDa} \text { protein } 5 \text { (glucose- } \\
\text { regulated protein, } 78 \mathrm{kDa} \text { ) }\end{array}$ & $6.16 \mathrm{E}-09$ & -1.58323 \\
\hline KIAA1199 & $\begin{array}{l}57214,29213,10519 \\
608366\end{array}$ & CCSP1, TMEM2L & KIAA1199 & $2.04 \mathrm{E}-07$ & -2.37495 \\
\hline LIPG & $\begin{array}{l}9388,6623,04730 \\
603684\end{array}$ & $E D L, E L, P R 0719$ & lipase, endothelial & $3.29 \mathrm{E}-06$ & -1.62776 \\
\hline MANF & $7873,15461,601916$ & ARMET, ARP & $\begin{array}{l}\text { mesencephalic astrocyte-derived } \\
\text { neurotrophic factor }\end{array}$ & 3.09E-05 & -1.56615 \\
\hline MEAF6 & $\begin{array}{l}64769,25674,13347 \\
611001\end{array}$ & $\begin{array}{l}\text { C1orf149, CENP-28, } \\
\text { EAF6, NY-SAR-91 }\end{array}$ & MYST/Esa1-associated factor 6 & 0.046387 & 1.6122 \\
\hline MFAP4 & \multicolumn{2}{|l|}{$4239,7035,600596$} & microfibrillar-associated protein 4 & 0.000298 & -1.76449 \\
\hline MGP & $4256,7060,154870$ & GIG36, MGLAP, NTI & matrix Gla protein & $7.10 \mathrm{E}-05$ & -1.93453 \\
\hline NQO1 & $1728,2874,125860$ & $\begin{array}{l}\text { DHQU, DIA4, DTD, } \\
\text { NMOR1, NMORI, } \\
\text { QR1 }\end{array}$ & $\mathrm{NAD}(\mathrm{P}) \mathrm{H}$ dehydrogenase, quinone 1 & $4.58 \mathrm{E}-06$ & 1.59138 \\
\hline NRP2 & $\begin{array}{l}8828,8005,03643 \\
602070\end{array}$ & $\begin{array}{l}\text { NP2, NPN2, } \\
\text { PRO2714, } \\
\text { VEGF165R2 }\end{array}$ & neuropilin 2 & $5.10 \mathrm{E}-05$ & -1.56606 \\
\hline PSG5 & $5673,9522,176394$ & FL-NCA-3, PSG & pregnancy specific beta-1-glycoprotein 5 & $2.42 \mathrm{E}-07$ & 2.38656 \\
\hline PTGIS & $\begin{array}{l}5740,9603,09046 \\
601699\end{array}$ & $\begin{array}{l}\text { CYP8, CYP8A1, } \\
\text { PGIS, PTGI }\end{array}$ & prostaglandin I2 (prostacyclin) synthase & $2.16 \mathrm{E}-06$ & -1.7082 \\
\hline PTX3 & $5806,9692,602492$ & TNFAIP5, TSG-14 & pentraxin 3 , long & 0.000102 & 1.7074 \\
\hline RARB & $5915,9865,180220$ & $\begin{array}{l}\text { HAP, MCOPS12, } \\
\text { NR1B2, RRB2 }\end{array}$ & retinoic acid receptor, beta & $6.47 \mathrm{E}-06$ & -1.58753 \\
\hline RARRES1 & $5918,9867,605090$ & LXNL, TIG1 & $\begin{array}{l}\text { retinoic acid receptor responder (tazarotene } \\
\text { induced) } 1\end{array}$ & 0.000351 & -1.86968 \\
\hline RCAN1 & $1827,3040,602917$ & $\begin{array}{l}\text { ADAPT78, CSP1, } \\
\text { DSC1, DSCR1, } \\
\text { MCIP1, RCN1 }\end{array}$ & regulator of calcineurin 1 & 0.000671 & -1.54455 \\
\hline SLC7A2 & $6542,11060,601872$ & $\begin{array}{l}\text { ATRC2, CAT2, } \\
\text { HCAT2 }\end{array}$ & $\begin{array}{l}\text { solute carrier family } 7 \text { (cationic amino acid } \\
\text { transporter, } y+\text { system), member } 2\end{array}$ & 0.000133 & 1.56978 \\
\hline TFRC & $7037,11763,190010$ & $\begin{array}{l}\text { CD71, p90, T9, TFR, } \\
\text { TFR1, TR, TRFR }\end{array}$ & transferrin receptor & $1.58 \mathrm{E}-05$ & 1.64566 \\
\hline ZNF185 & \multicolumn{2}{|l|}{$7739,12976,300381$} & zinc finger protein 185 (LIM domain) & $3.44 \mathrm{E}-05$ & 2.38507 \\
\hline
\end{tabular}

